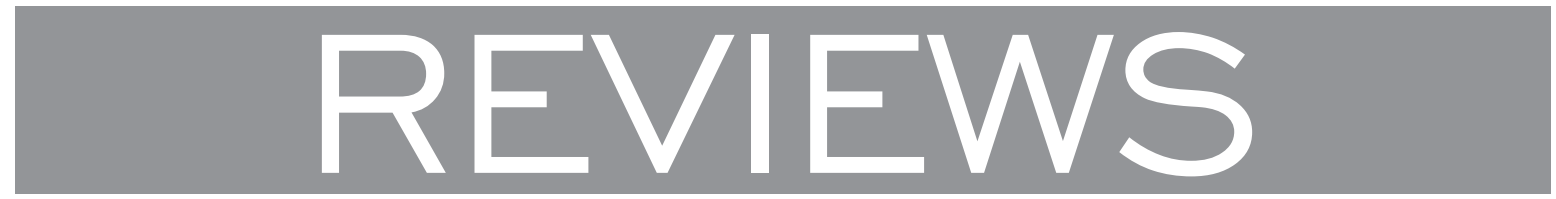

Ecological Monographs, 88(2), 2018, pp. 141-169

(C) 2018 by the Ecological Society of America

\title{
Fire-induced deforestation in drought-prone Mediterranean forests: drivers and unknowns from leaves to communities
}

\author{
Asaf Karavani, ${ }^{1}$ Matthias M. Boer, ${ }^{2}$ Mara Baudena, ${ }^{3}$ Carlos Colinas, ${ }^{4}$ Rubén Díaz-Sierra,,${ }^{5}$ Jesús Pemán, ${ }^{4}$ \\ Martín de Luis, ${ }^{6}$ Álvaro Enríquez-de-Salamanca iD ${ }^{5}$ and Víctor Resco de Dios (iD 4,7 \\ ${ }^{1}$ Master Course Mediterranean Forestry and Natural Resources Management, Universitat de Lleida, E25198 Lleida, Spain \\ ${ }^{2}$ Hawkesbury Institute for the Environment, Western Sydney University, Richmond, New South Wales 2753 Australia \\ ${ }^{3}$ Copernicus Institute of Sustainable Development, Environmental Science Group, Utrecht University, P. O. Box 80115, \\ 3508 TC Utrecht, The Netherlands \\ ${ }^{4}$ Department of Crop and Forest Sciences-AGROTECNIO Center, Universitat de Lleida, E 25198 Lleida, Spain \\ ${ }^{5}$ Mathematical and Fluid Physics Department, Faculty of Sciences, Universidad Nacional de Educación a Distancia, Madrid 28040 Spain \\ ${ }^{6}$ Department of Geography and Regional Planning, University of Zaragoza, 50009 Zaragoza, Spain
}

Abstract. Over the past 15 years, 3 million hectares of forests have been converted into shrublands or grasslands in the Mediterranean countries of the European Union. Fire and drought are the main drivers underlying this deforestation. Here we present a conceptual framework for the process of fire-induced deforestation based on the interactive effects of fire and drought across three hierarchical scales: resistance in individuals, resilience in populations, and transitions to a new state. At the individual plant level, we review the traits that confer structural and physiological resistance, as well as allow for resprouting capacity: deforestation can be initiated when established individuals succumb to fire. After individuals perish, the second step toward deforestation requires a limited resilience from the population, that is, a reduced ability of that species to regenerate after fire. If individuals die after fire and the population fails to recover, then a transition to a new state will occur. We document trade-offs between drought survival and fire survival, as embolism resistance is negatively correlated with fire tolerance in conifers and leaf shedding or drought deciduousness, a process that decreases water consumption at the peak of the dry season, temporally increases crown flammability. Propagule availability and establishment control resilience after mortality, but different hypotheses make contrasting predictions on the drivers of post-fire establishment. Mycorrhizae play an additional role in modulating the response by favoring recovery through amelioration of the nutritional and water status of resprouts and new germinants. So far, resprouter species such as oaks have provided a buffer against deforestation in forests dominated by obligate seeder trees, when present in high enough density in the understory. While diversifying stands with resprouters is often reported as advantageous for building resilience, important knowledge gaps exist on how floristic composition interacts with stand flammability and on the "resprouter exhaustion syndrome," a condition where pre-fire drought stress, or short fire return intervals, seriously restrict post-fire resprouting. Additional attention should be paid to the onset of novel fire environments in previously fire-free environments, such as high altitude forests, and management actions need to accommodate this complexity to sustain Mediterranean forests under a changing climate.

Key words: climate change; community dynamics; drought; fire; land degradation; Mediterranean forests; state and transition; stress physiology.

\section{INTRODUCTION}

Mediterranean ecosystems occupy a modest $2 \%$ of the terrestrial biosphere, but host $15 \%$ of the global flora, provide erosion control, water regulation, wood, and

Manuscript received 10 April 2017; revised 23 October 2017; accepted 26 October 2017. Corresponding Editor: Carolyn H. Sieg.

${ }^{7}$ Corresponding author; e-mail: v.rescodedios@gmail.com many other vital goods and services (Rundel 2007, Shakesby 2011, Büntgen et al. 2012, Bonet et al. 2014). Moreover, Mediterranean and semiarid ecosystems play an important role as climate regulators by mediating in the biosphere-atmosphere exchanges of carbon and energy (Rotenberg and Yakir 2010).

One of the major factors controlling the goods and services provided by Mediterranean ecosystems is landscape physiognomy, with shrublands and grasslands 
showing higher erosion and albedo, as well as lower $\mathrm{C}$ sequestration and latent heat exchange than forests, among other important differences (Chapin et al. 2008). Land surface "greenness" has, overall, increased in the Mediterranean EU countries during the past few years: 2.3 Mha occupied by shrubland in 1990 had become forest by 2006 , and 2.0 Mha of agricultural land had become shrubland or forest within the same time frame (San-Miguel-Ayanz et al. 2012). However, this greening trend has been partly counteracted by the transformation of 3.2 Mha of forest into shrubland, with fire and drought identified as the main causal factors for that physiognomic shift (San-Miguel-Ayanz et al. 2012).

Here we review the literature on the processes underlying fire-induced physiognomic changes, including deforestation, in the Mediterranean countries of the European Union, focusing on the interactions between drought and fire in particular. Our ultimate goal is to develop a bottom-up conceptual model to gain understanding of when forests fail to recover after fire, on how pre- vs. post-fire drought modulates responses across landscapes, and to highlight emerging knowledge gaps. This review is timely because, under climate change, both severe fire weather and drought are expected to become more frequent in the Mediterranean basin (Roderick et al. 2014, Bedia et al. 2015). While Mediterranean environments are characterized by a summer drought (e.g., period of limited rainfall and high evaporative demand), IPCC (Intergovenmental Panel on Climate Change) predictions forecast an increase in the duration and intensity of the summer drought (IPCC 2014), which could lead to extreme water scarcity, eventually enhancing tree mortality. Drought-induced mortality has been documented (McDowell et al. 2008, Anderegg 2015, Mencuccini et al. 2015), but comprehensive syntheses on how fire and an intensifying summer drought interact to drive physiognomic changes are still missing. We will not cover all aspects of secondary succession as extensive reviews on the topic are available elsewhere (Bazzaz 1979, Schulze et al. 2005, Pulsford et al. 2016). Instead, here we concentrate on some recent advances and research gaps that need addressing to successfully predict transformational changes to non-forest states under fire and drought.

The manuscript develops the mechanisms explaining non-linear responses and ecosystem resistance and resilience to forest fires through a hierarchical, bottom-up approach. We begin with a general description of the spatial drivers of fire activity (pyrogeography) in the Mediterranean EU and of some expected changes under projected future climate, followed by a more specific discussion of the fire regime in the Mediterranean. Next, we summarize current literature on post-fire state transitions to develop a conceptual, three-step model describing the conditions under which post-fire deforestation occurs. Then, in the following three sections, we expand this conceptual model to explore, in more depth, the mechanisms underlying resistance to fire in individuals, resilience in populations, and state changes in communities. Here we use the term resistance to indicate whether individuals survive the fire and resilience to denote that individuals perish but the stand recovers via regeneration. We conclude this review highlighting some of the additional unresolved issues to predict post-fire deforestation.

\section{Mediterranean Pyrogeography Under Climate Change}

A general first-order approximation to global fire activity is provided by the "intermediate-fire productivity" hypothesis (Pausas and Bradstock 2007, Keeley et al. 2012, Pausas and Ribeiro 2013), which assumes a tradeoff between productivity and aridity, and shows how relationships between fire and productivity, and between fire and aridity, are hump-shaped (Fig. 1). Peaks in global fire activity occur at intermediate levels of productivity and aridity, while minimum fire activity is observed where (1) productivity is low and aridity is high (deserts), as there is not enough biomass (i.e., fuel) to carry a fire, or (2) productivity is high and aridity is low (tropical rainforests), as potential fuels are seldom dry enough to burn.

This hypothesis is generally accepted (Holz et al. 2012, Boer et al. 2016) and allows for predictions on how global change has affected, and will continue to

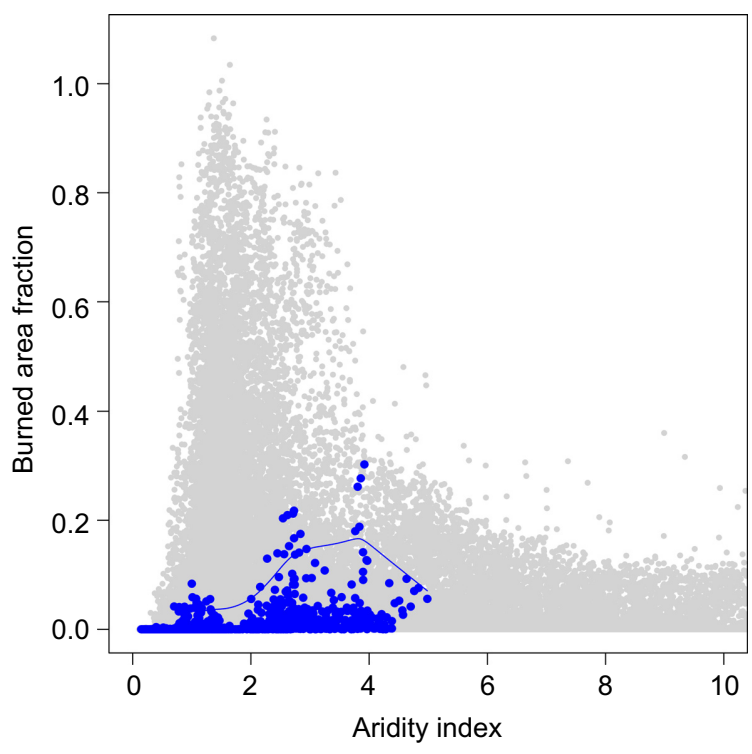

FIG. 1. Relationship between global (gray) mean annual burned area fraction (1996-2012) and the aridity index (the ratio between mean annual potential evapotranspiration to precipitation). European points are highlighted in blue (grid cells, $0.25^{\circ} \times 0.25^{\circ}$ ), and the line indicates the 0.99 quantile. If aridity increases as a result of climate change, we can expect fire activity to follow a non-linear trend across aridity gradients, with increasing fire activity at the wetter end of the spectrum and lower fire activity toward the drier end due to fuel limitations. Mean annual burned from the GFED4 data set (Giglio et al. 2013), PET from the CGIAR-CSI data set (Zomer et al. 2008), and P from WorldClim (Hijmans et al. 2005). We used European (and not Mediterranean only) to increase data coverage at both sides of the hump. 
affect, the vulnerability of Mediterranean forests to fire. Indeed, because fuel loads are generally large enough to sustain fires, increasing aridity from climate change could lead to more extreme fire weather in Mediterranean forests (Moreno et al. 2013). Increases in fire activity are unlikely to occur at the same rate across landscapes, and we can expect them to be linked to productivity gradients (McKenzie and Littell 2016) and human activity (Knorr et al. 2016). Higher relative increases in fire activity are expected to occur at the most productive Mediterranean forests (where higher continuous fuel loads are present and increased aridity will increase fuel dryness), and smaller increases or even reductions in fire activity have been predicted where water limitations are strongest (where already low fuel loads could be reduced even further, Fig. 1; Batllori et al. 2013). That is, fuel limitations may limit fire activity toward the drier end of the Mediterranean basin.

Projected increases in aridity could, at least in part, be counteracted by increases in $\mathrm{CO}_{2}$ concentrations, as water use efficiency has often been reported to increase throughout this century (Granda et al. 2014). Increasing $\mathrm{CO}_{2}$ concentrations could potentially also affect leaf flammability as leaves under elevated $\mathrm{CO}_{2}$ tend to be thicker (higher leaf mass per area; Peñuelas and Matamala 1990), which would, in turn, alter leaf-level flammability by lowering ignitability and increasing fire sustainability (Grootemaat et al. 2015). However, there is a paucity of data on $\mathrm{CO}_{2}$ effects overall on leaf-tostand flammability and on the extent to which changes in leaf thickness translate into changes in fire behavior (Rothermel 1972, Madrigal et al. 2011, Fernandes and Cruz 2012). Additionally, $\mathrm{CO}_{2}$ could potentially impact stand-level flammability in Mediterranean environments by enhancing productivity and fuel growth (Resco de Dios et al. 2016), however, potential fertilization effects in the region remain contentious (Camarero et al. 2015, Fernández-de-Uña et al. 2016).

\section{Fire regime in the Mediterranean}

Fire effects in Mediterranean ecosystems, like in other biomes, may be better understood within the fire regime framework (Keeley et al. 2012), which maintains that the effects of fire as a driver of vegetation change depend upon the type of fuels consumed, the recurrence and seasonality of fires, as well as the intensity, severity, and burned patch size (Gill 1973, Keeley et al. 2009). Forest fires, from the point of view of the vegetation burned, are often classified as ground fires, surface (or understory) fires, or crown fires, and there are different types of crown fires (e.g., active vs. passive, dependent vs. independent; Scott et al. 2014). These classifications are useful for understanding, among others, fire behavior and they will determine fire extinction operations. However, from the point of vegetation dynamics, we argue that interactions of fire type with intensity and severity are particularly important. This is because survival, particularly for seeder trees, largely depends upon the degree of canopy scorch. Consequently, while active or independent crown fires will lead to canopy consumption, surface fires with a large accumulation of understory fuel or under strong wind could also lead to canopy defoliation and bud scorch and exert a similar impact on vegetation. As we will describe later in further detail, Mediterranean environments often show either low-intensity surface fires or high-intensity crown defoliating fires and different plant strategies have evolved to maintain species and populations under these different fire environments.

Estimating fire frequency and recurrence in Mediterranean Europe is complicated because most forests in the area are relatively young (originated either after oldfield abandonment or reforestations) or have a long history of exploitation that hinders dendrological analyses. In California, average fire rotation intervals have been estimated to be 36 years, but high intra-regional variation exists (Keeley et al. 1999). Human actions have had a large impact on fire frequency. For instance, fire frequency in Valencia (western Mediterranean basin) has been estimated to have doubled after the 1970s due to land abandonment (Pausas and Fernández-Muñoz 2011). Fire frequencies are another important element affecting deforestation, particularly for those species that regenerate from seeds, because a certain fire-free interval is necessary to achieve maturity and produce viable seeds. Similarly, fire size has been dramatically altered after decades of fire suppression. A remarkable consequence of the effect of fire suppression is the so-called fire paradox, whereby a large proportion of the total burned area is consumed in a few large events. For instance, in the case of Catalonia (northeastern Spain) only $0.2 \%$ of all forest fires are large fires ( $>500 \mathrm{ha}$ ) but they consume over $60 \%$ of the total area burned. Consequently, the fire size distribution is extremely skewed, with a large proportion of small fires, that may be easily controlled, but a small proportion of large fires, that are beyond extinction capacity, and that consume a disproportionate portion of the land (Piñol et al. 2005).

Most forest fires in the Mediterranean occur in the summer, during periods of water scarcity (Urbieta et al. 2015). It has been argued that a change in the fire regime has occurred during the 20th century, where fire activity was limited by fuel activity up to the 1970s, and that it has been driven by drought ever since (Pausas and Fernández-Muñoz 2011). However, if drought advances under climate change, as predicted by IPCC scenarios (IPCC 2014), fire regimes in Mediterranean ecosystems may again become fuel limited due to limitations to plant productivity under increasing water scarcity. The seasonality of forest fires and, particularly, the levels of pre- and post-fire water availability will differentially impact postvegetation recovery as a function of the traits present in the community, as we will discuss later on.

Whereas we do not seek to provide a full review of fire regimes, it is worth noting that there is an extensive body 
of the literature on the degree to which fuel vs. weather control fire regimes in the Mediterranean. Broadly speaking, forest fires from the point of view of fire behavior may be classified as topography driven, wind driven, or as convective fires (Duane et al. 2015). Topography-driven fires are driven by the effects of local slopes on the heating and cooling of local air and consequently, air movement, over diurnal cycles. Wind-driven fires have fast spread rates and often reach high intensities. Convective forest fires result from large accumulations of fuel interacting with specific atmospheric conditions and lead to very high fire intensities that spread through airstreams created through the convection created by the fire. Fuel has been determined to be one of the major determinants of convective fires, but landscape and climatic factors have a more important effect over topographic and wind-driven fires (Duane et al. 2015). The type of fire propagation has important effects on the fire regime because, for instance, convective fires will burn under high intensity but low frequency, whereas topographic fires will tend to burn under lower intensity and higher frequency; although this is a simplification of reality and topographic fires may also lead to high intensities. Wind-driven fires will also lead to high-intensity and fast-spreading fires.

\section{Alternative States in Post-Fire Regeneration and Processes Conducive to Deforestation}

The general process of post-fire deforestation is summarized in Fig. 2. In its simplest form, fire-induced deforestation could be conceptualized as a three-step process

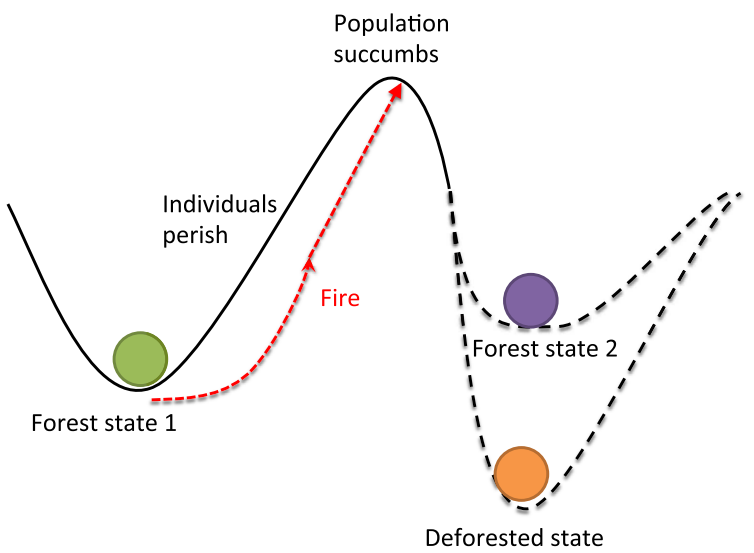

FIG. 2. Concepual framework for the mechanisms of fireinduced deforestation operating across three hierarchical scales: resistance in individuals, resilience in populations, and transition to a new community. The first requirement for fire-induced deforestation is the mortality of individuals. After individuals perish, the second step toward deforestation requires a limited resilience from the population, that is, an inability of that species to regenerate after fire. If individuals die after fire and the population fails to recover, then a species replacement or transition to a new state must occur. In this third step, the community could switch toward a more advanced successional stage or toward deforestation, depending on different factors. operating at a hierarchy of scales, where the fire regime interacts with individual-, population-, and communitylevel traits. The first step depends on the resistance of individual trees to fire, i.e., for deforestation to occur, individual trees must succumb to fire, a process affected by fire intensity (energy release) and severity (ecological impact; Keeley 2009), and by the type of fuels consumed. After individuals perish, the second step toward deforestation depends on the resilience of the population, that is, the ability of that species to regenerate after fire, where fire recurrence plays a major influence. If individuals die after fire and the population fails to recover, then a species replacement or state transition is likely, a process dependent on burned patch size and fire seasonality among others. If the transition is toward a non-forest state, the third step toward deforestation is effectuated.

This conceptual model can further increase our understanding of the post-fire deforestation of Mediterranean ecosystems that, so far, has been mostly limited to Pinus (pine)-dominated communities (Martín-Alcón et al. 2015, Torres et al. 2016). Mediterranean pines lack the capacity to resprout and their regeneration relies upon post-fire seed germination. Deforestation in the region could thus be considered as dependent on the concurrence of three conditions: (1) fatal damage to the trees and to the seeds (e.g., no aerial or soil seed banks) after the fire, (2) lack of adult conspecifics that may act as seed sources within dispersal distances (usually $<100 \mathrm{~m}$ in pines; Rodrigo et al. 2007), and (3) absence of resprouting trees in the understory. When only (1) and (2) are met, but oaks (Quercus) are present in the understory, then a pine-to-oak transition is likely. However, when conditions 1 and 2 concur, and no resprouting trees are present in the understory, deforestation is the final result of this process.

Additionally, although the bulk of post-fire deforestation so far has occurred in pine forests, we cannot ignore deforestation in resprouting forests also under a warmer and drier future. This is because, for instance, oak decline is already occurring over a large proportion of the Mediterranean (Peguero-Pina et al. 2015, Barbeta and Peñuelas 2016, Gómez-Aparicio et al. 2017) and resprouting tree species are being displaced by seeder and resprouting shrub species under drought (Peñuelas et al. 2017). Consequently, fire may further promote forest-toshrub state transitions in oak or resprouter forests.

Such vegetation changes have been classically framed as advancing (pine-to-oak) or reversing (pine-to-shrubland) successional dynamics (Hanes 1971, Trabaud 1984). This approach presents succession as a linear process where vegetation advances, in the absence of disturbance, toward an end point (climax) and, when disturbances occur, vegetation returns to a previous state along that linear pathway. However, we prefer to describe them within a state-transition framework, because successional trajectories are often difficult to predict and non-linear. According to the traditional model of successional dynamics, based on a phytosociological perspective, 
Quercus would often be the predominant natural potential vegetation for much of the Mediterranean basin (Rivas-Martínez et al. 2005). However, palynological evidence has in many occasions documented lack of support for predictions from phytosociological hypotheses on what the late successional vegetation for a given area would be (Carrión and Fernández 2009). Additionally, field studies report non-linear trajectories, meaning that interactions with local idiosyncrasies may lead to different post-fire communities at a given site. For instance, Baeza et al. (2007) documented how, for different fire recurrences, different shrub communities could arise after fire at Pinus halepensis (Aleppo pine) stands as a function of local processes such as soils.

Given all these non-linear responses, involving a high degree of complexity (Fig. 3, Table 1), predicting largescale tree mortality and resprouting capacity after fire, especially under a climate with increasing aridity, remains an important challenge (Midgley et al. 2010, Clarke et al. 2013). Below we will discuss the main knowns and unknowns associated with each of the three steps.

\section{Fire Resistance at Individual Tree Level}

Crown defoliating fires are a common fire type in Mediterranean type ecosystems (Keeley et al. 2012). Post-fire survival is therefore very low among nonresprouter trees, where crown combustion or substantially high crown scorch are the most common cause of mortality, especially among the less fire-tolerant species (Sieg et al. 2006). However, there are traits that can enhance the survival of individuals under certain conditions, and some of these traits are thought to be fire adaptations (Keeley et al. 2012). Here we will classify these traits as (1) structural traits, which reduce fire intensity and severity; (2) physiological traits, which explain how trees succumb to fire; and (3) resprouting traits, which enable post-fire regeneration by resprouting. The distinction between these different classes is not clear-cut, but reflects different approaches to study fire effects. Understanding these traits will be important not only for understanding fire-induced mortality and to inform management on fuel reduction treatments, but also to understand potential for evolutionary trade-offs. Because fires and summer droughts often co-occur in Mediterranean ecosystems (although large fires could occur at any other times of year, provided that dead fine fuels are sufficiently dry and winds are sufficiently strong), and because pre-fire water scarcity could act as a priming for post-fire mortality (van Mantgem et al. 2013), it is particularly important to understand potential relationships between traits that confer fire resistance and its interaction with drought resistance (Fig. 3a, Table 1).

\section{Structural traits}

Fuel moisture.-Different structural traits assist in reducing tree flammability, or the likelihood that a tree burns.
One of them is fuel moisture, as fires only occur when the fuel is dry enough to burn (Dennison et al. 2008, Nolan et al. 2016). The most limiting step for fire propagation is the moisture content of dead fine fuel, but this is beyond the control of the plant and will not be covered further here. The impact of live fuel moisture on the rate of fire spread is often thought to be marginal compared with other influences (Alexander and Cruz 2013, Anderson et al. 2015). However, studies on thresholds for fire occurrence report important increases in burned area as live fuel moisture content (LFMC) in fine live fuels $(<3 \mathrm{~mm}$ thick, mainly leaves and twigs) drops below $100 \%$ in southeastern Australian forests (Nolan et al. 2016) and below $70 \%$ in Mediterranean shrublands (Dennison et al. 2008, Jurdao et al. 2013). While Mediterranean shrubs may be able to withstand much lower relative water contents than trees due to their capacity for osmotic and/or elastic adjustments (Pellizzaro et al. 2007, Ramírez et al. 2012), the reason why these thresholds vary across functional types remains elusive. Deciduous trees usually have higher LFMC than evergreen trees since the foliage of the former contain only young leaves produced in the same year. Another difference between LFMC in shrubs and evergreen Mediterranean trees is that while the former often exhibit seasonal patterns in LFMC, evergreen trees in Mediterranean environments are characterized by quite stable foliar moisture contents throughout the year (Viegas et al. 2001, Soler Martin et al. 2017). At any rate, the dynamics of fuel moisture consequently determine fire seasonality, establishing one of the primary links between drought and the fire regime.

Mechanistic modeling of LFMC has so far been remarkably difficult. The physiological literature is rich in modeling leaf water potentials (Sperry et al. 1998, Tuzet et al. 2003, Duursma and Medlyn 2012), but the translation of water potential to LFMC is not straightforward because (1) the physiological literature uses relative water content (RWC, expressed on the basis of saturated minus dry mass) while the fire literature uses LFMC (expressed on a dry mass content basis); (2) the relationship between water potential and RWC is not constant through time and depends upon osmotic and elastic adjustments, which are more difficult to model; and (3) while there might be small differences in water potential between branches and leaves, differences in LFMC might be more marked, which additionally complicates the translation of one measurement into the other across organs.

Another feature that potentially increases crown flammability temporally and, thereby, the probability of crown fire, is leaf senescence during drought, which leads to high accumulations of dry leaves in the canopy. For instance, leaf life span in Pinus halepensis is approximately three years (Mediavilla et al. 2008), and threeyear-old needles typically become dry and senesce at the peak of the fire season (July), potentially leading to onethird of the canopy being composed of dry matter, which enhances crown flammability substantially (Fig. 4). However, this effect is only transient and lasts for a few 

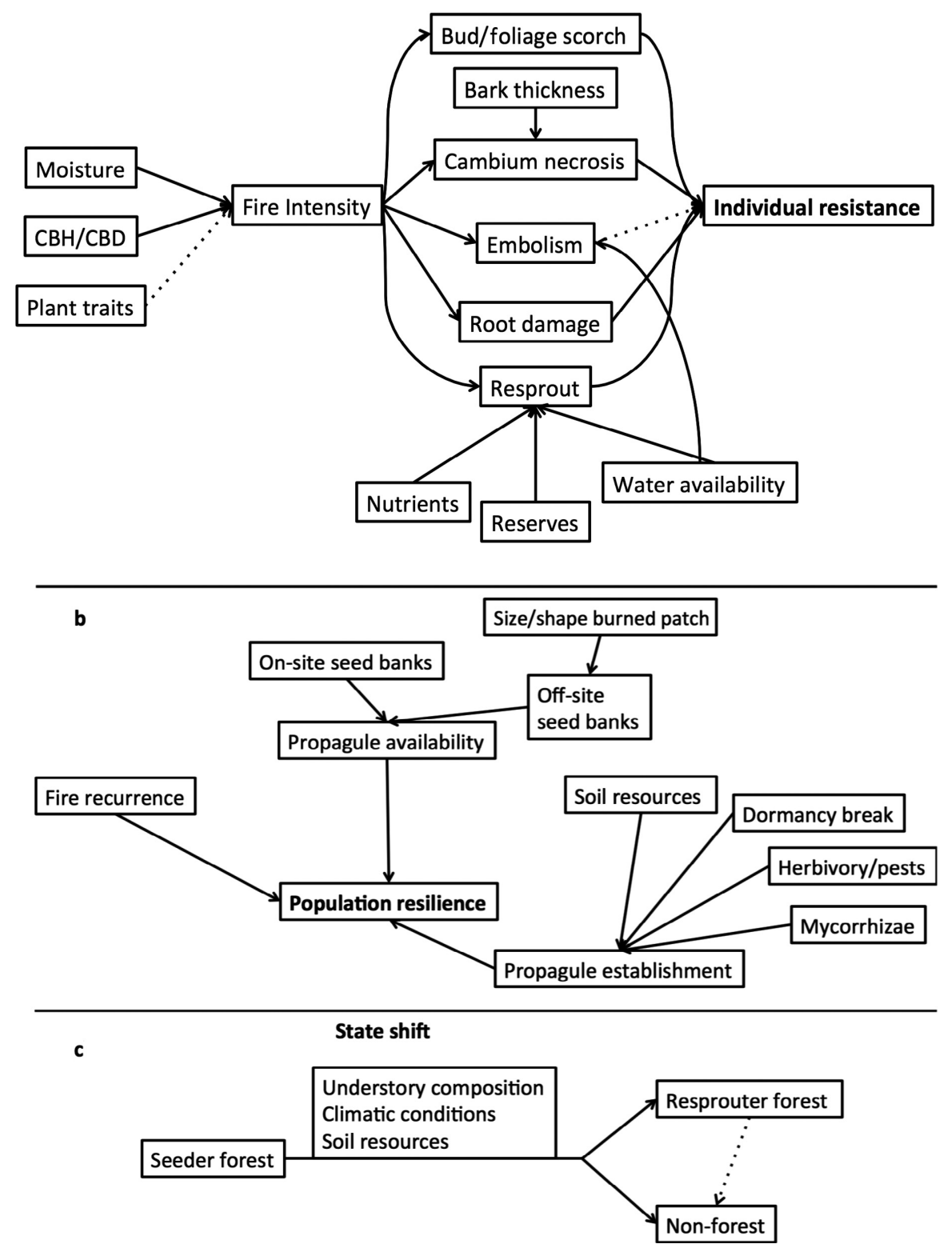

FIG. 3. Post-fire vegetation dynamics are highly complex. A multitude of processes interact at different scales to affect individual resistance, population resilience, and state transitions. (a) State transitions initiate after a fire kills pre-existing individuals, and a series of factors affect individual resistance to fire. (b) After individuals perish, stand-level resilience (where pre-fire species are able to regenerate), depends on fire history and recurrence, propagule availability, and establishment. (c) If pre-fire individuals perish and populations cannot recover, a state shift is effectuated. The state will transition to a different forest state or to a deforested state depending on legacies from pre-fire understory composition, soil resources, and climatic pressures. Solid and dotted lines indicate processes that are well-documented or that have been hypothesized but remain in discussion, respectively. Further discussions, and knowns and unknowns associated within each step are in Fire Resistance at Individual Tree Level; Resilience to Fire at Population Level and State Transitions after Fire and Changes in Community Dominance and in Table 1.

weeks, until leaf dropping. After the old leaves are shed, the probability of active crowning could decline (if the drop in canopy bulk density is high enough) and surface fires may become more likely and, potentially, more intense due to higher fuel load (note that the flammability of the surface fuel bed will also be affected by leaf traits that influence the packing and aeration of the fuel bed [Ganteaume et al. 2014, Cornwell et al. 2015], but a full review of leaf traits and surface fuel is beyond the scope of this article). Such leaf senescence (that later leads to shedding in evergreens or drought deciduousness in deciduous species) may be adaptive for 
TABLE 1. Processes affecting state transitions and community change after fire in a forest stand. Interactions in Fig. 3.

\begin{tabular}{|c|c|c|}
\hline Process & Knowns & Unknowns \\
\hline \multicolumn{3}{|l|}{ Individual resistance } \\
\hline Live fuel moisture & $\begin{array}{l}\text { Remains stable and generally available in } \\
\text { evergreen trees but shows seasonal } \\
\text { fluctuations in shrubs, affecting fuel } \\
\text { availability and, consequently, potential fire } \\
\text { behavior }\end{array}$ & $\begin{array}{l}\text { Modeling remains elusive as well as links with the } \\
\text { closely related field of plant water relations. The } \\
\text { phenology of leaf senescence could lead to trade- } \\
\text { offs between drought and fire resistance }\end{array}$ \\
\hline $\begin{array}{l}\text { Crown Base height/ } \\
\text { Canopy bulk density }\end{array}$ & $\begin{array}{l}\text { Determines probability and spread of a crown } \\
\text { fire. It could be a niche construction } \\
\text { mechanism. }\end{array}$ & $\begin{array}{l}\text { Measuring CBD is notoriously difficult and data } \\
\text { available only covers a few species. Heuristic } \\
\text { predictions are used elsewhere, which limits fire } \\
\text { behavior simulations. }\end{array}$ \\
\hline Plant traits & $\begin{array}{l}\text { Changes in surface leaf area or chemical leaf } \\
\text { composition could alter leaf flammability. }\end{array}$ & $\begin{array}{l}\text { Whether and how leaf-level flammability scales to } \\
\text { canopy level remains contentious. }\end{array}$ \\
\hline Bark & $\begin{array}{l}\text { Increasing thickness, density, smoothness, } \\
\text { water content, and decreasing fissures } \\
\text { enhance cambial protection and subsequent } \\
\text { survival in surface fires. }\end{array}$ & $\begin{array}{l}\text { Understanding how fire protection interacts with } \\
\text { additional bark functions, such as water and } \\
\text { photosynthate storage, as drivers of bark ecology } \\
\text { and evolution. }\end{array}$ \\
\hline Roots & $\begin{array}{l}\text { Direct effects of fire on roots are rare, given } \\
\text { the thermal buffering capabilities of soils. }\end{array}$ & $\begin{array}{l}\text { Main unknowns relate to its role as a storage organ } \\
\text { for resprouting. }\end{array}$ \\
\hline $\begin{array}{l}\text { Physiological } \\
\text { processes: scorch, } \\
\text { girdling, and } \\
\text { cavitation }\end{array}$ & $\begin{array}{l}\text { Foliage and bud scorch are the main factor } \\
\text { driving post-fire mortality in crown fires. } \\
\text { Cambium necrosis plays a secondary role. }\end{array}$ & $\begin{array}{l}\text { Whether catastrophic xylem failure is involved in } \\
\text { post-fire death, particularly in low-intensity fires or } \\
\text { in the individuals dying in the weeks to months } \\
\text { after the fire is under discussion. Trade-offs between } \\
\text { embolism and fire resistances could occur. }\end{array}$ \\
\hline Resprouting & $\begin{array}{l}\text { Driven by the interaction between the } \\
\text { availabilities of water, nutrients and reserves. } \\
\text { There are indications of reduced resprouting } \\
\text { vigor after successive fire events. }\end{array}$ & $\begin{array}{l}\text { Understanding whether water stress antecedent to } \\
\text { the fire will eventually lead to a resprout exhaustion } \\
\text { syndrome, and what is the most limiting } \\
\text { mechanism: cavitation fatigue vs. reserve exhaustion }\end{array}$ \\
\hline \multicolumn{3}{|l|}{ Population resilience } \\
\hline Propagule availability & $\begin{array}{l}\text { Post-fire regeneration in seeder species relies } \\
\text { on seed banks relies or on seed from } \\
\text { adjacent unburned stands. Critical distances } \\
\text { for pine species have been reported to be } \\
<100 \mathrm{~m} \text {. The size of the burned patch is thus } \\
\text { critical in species with no seed banks. }\end{array}$ & $\begin{array}{l}\text { Factors driving seed production and dispersal remain } \\
\text { difficult to incorporate within mechanistic modeling } \\
\text { frameworks. }\end{array}$ \\
\hline $\begin{array}{l}\text { Propagule } \\
\text { establishment }\end{array}$ & $\begin{array}{l}\text { Interactions between soil resources, dormancy } \\
\text { break, herbivores and pests, and microsite } \\
\text { conditions driver establishment. }\end{array}$ & $\begin{array}{l}\text { Competing hypotheses on pre-vs. post-fire conditions } \\
\text { make different predictions on the drivers of } \\
\text { establishment. Neutral processes remain } \\
\text { understudied in the area. }\end{array}$ \\
\hline Fire recurrence & $\begin{array}{l}\text { A single crown fire may induce deforestation } \\
\text { in forests dominated by seeder trees that lack } \\
\text { seed banks. Species with seed banks will need } \\
\text { at least } 8-10 \text { yr to become mature and set } \\
\text { seed and increasing fire recurrences may } \\
\text { subsequently induce deforestation. }\end{array}$ & $\begin{array}{l}\text { Lack of resprouting under high fire recurrence has } \\
\text { not yet been broadly documented, but its potential } \\
\text { for occurrence is high given documented declines in } \\
\text { resprouting vigor. }\end{array}$ \\
\hline Mycorrhizal networks & $\begin{array}{l}\text { Prompt vegetation establishment after fire is } \\
\text { additionally required to preserve } \\
\text { ectomycorrhizal networks, as most tree } \\
\text { species in Mediterranean environments are } \\
\text { obligate ectomycorrhizal. }\end{array}$ & $\begin{array}{l}\text { An overall lack of data prevents an effective } \\
\text { synthesis, but there are hints that low-intensity fires, } \\
\text { such as prescribed burning, could be as negative as } \\
\text { in large fires. }\end{array}$ \\
\hline \multicolumn{3}{|l|}{ State shifts } \\
\hline $\begin{array}{l}\text { Legacies form pre-fire } \\
\text { composition }\end{array}$ & $\begin{array}{l}\text { The presence or absence of resprouting trees } \\
\text { in the understory will be the most important } \\
\text { requirement for determining whether post- } \\
\text { fire state change will be to a forest state } \\
\text { (dominated by resprouters) or to a } \\
\text { deforested state. }\end{array}$ & $\begin{array}{l}\text { The resprout exhaustion syndrome may reinforce } \\
\text { deforestation even in stands previously dominated } \\
\text { by resprouters. }\end{array}$ \\
\hline $\begin{array}{l}\text { Climatic conditions } \\
\text { and water balance }\end{array}$ & $\begin{array}{l}\text { Long-term precipitation patterns influence } \\
\text { the site productivity and, consequently the } \\
\text { general capability for the species to resprout } \\
\text { or to produce and establish propagules. } \\
\text { Short-term patterns of precipitation in the } \\
\text { next wet season after a fire will affect seed } \\
\text { establishment. }\end{array}$ & $\begin{array}{l}\text { Whether resprouters will be able to thrive under } \\
\text { future climatic conditions, of increased stress and } \\
\text { beyond climatic niches in some cases, deserves } \\
\text { further attention. Even if they can survive, a } \\
\text { reduced ability to resprout due to the resprouting } \\
\text { exhaustion syndrome might lead to an alternative } \\
\text { deforested state that is stable within ecological time } \\
\text { frames, although the stability and feasibility of this } \\
\text { state is not totally known. }\end{array}$ \\
\hline
\end{tabular}


TABLE 1. (Continued)

\begin{tabular}{|c|c|c|}
\hline Process & Knowns & Unknowns \\
\hline $\begin{array}{l}\text { Flammability } \\
\text { feedbacks }\end{array}$ & $\begin{array}{l}\text { Different species show different traits, such as } \\
\text { standing dead biomass, and those may } \\
\text { impact stand-level flammability. }\end{array}$ & $\begin{array}{l}\text { Whether species-level flammability attributes scale } \\
\text { up to affect fire behavior across landscapes remains } \\
\text { contentious. }\end{array}$ \\
\hline Soil resources & $\begin{array}{l}\text { Soil nutrients affect seed production and } \\
\text { resprouting vigor. Fires increase erosion and, } \\
\text { while temporally increasing nutrient } \\
\text { availability (by increasing mineralization), } \\
\text { they generally decrease total nutrient } \\
\text { concentrations. This effect may be } \\
\text { exacerbated under high fire recurrence. } \\
\text { Moreover, soil nutritional status diminishes } \\
\text { under post-fire shrub communities, relative to } \\
\text { pre-fire forest communities, further hindering } \\
\text { establishment of less frugal tree species. }\end{array}$ & $\begin{array}{l}\text { Extreme soil depletion could lead to an alternative } \\
\text { deforested state that is stable within ecological } \\
\text { timeframes, but a lack of literature prevents } \\
\text { assessments on the stability of the transition. }\end{array}$ \\
\hline
\end{tabular}

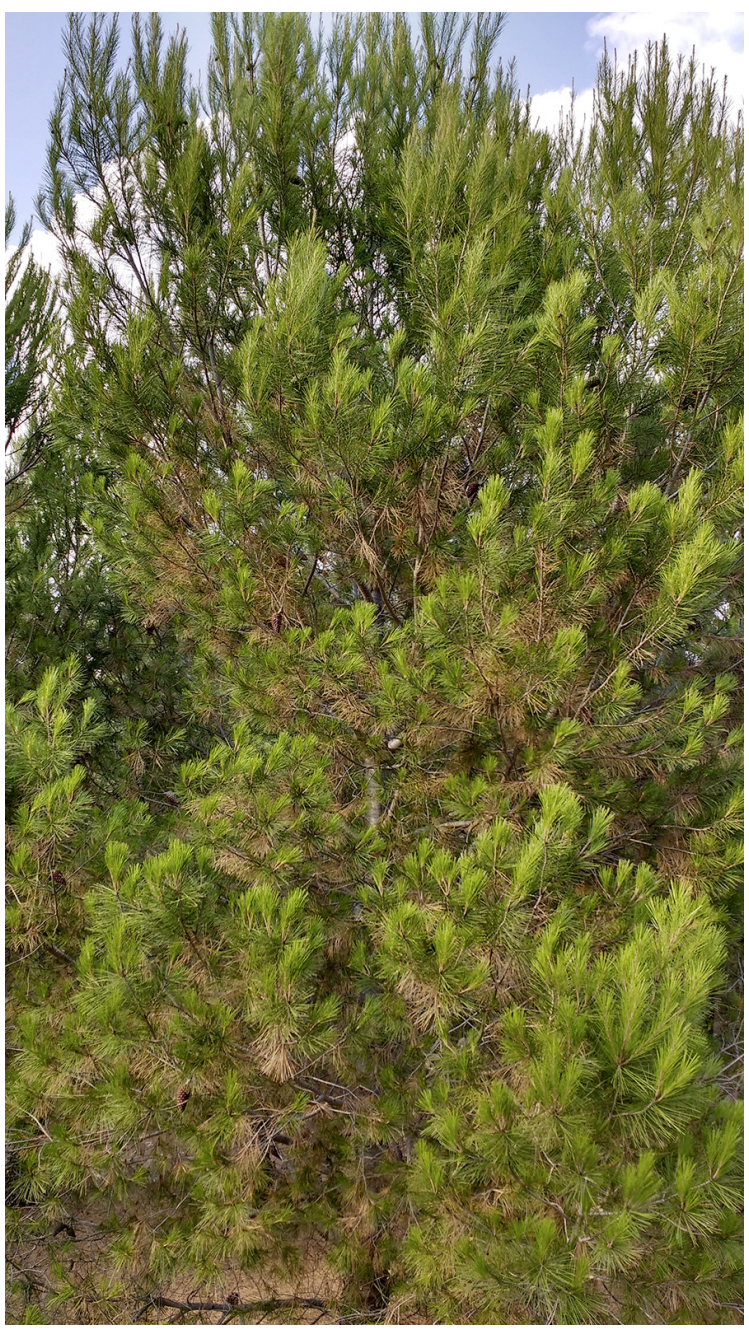

Fig. 4. Trade-offs between drought and fire survival. As summer drought advances, leaf shedding (in evergreens) or drought deciduousness occurs. This enhances drought survival by reducing water consumption by the canopy, but temporally increases crown flammability. In the photograph, 3-yr-old needles of Pinus halepensis senesce during late June and mid July (the part of the year with higher burned area in the region [MAGRAMA 2012]), until leaf drop a few weeks after. saving water in periods of protracted water scarcity, but it has the side effect of temporally enhancing stand flammability. Many studies report how some adaptations to fire help to cope with drought and that, conversely, some adaptations to water scarcity aid in surviving fires (Keeley et al. 2011). In fact, disentangling drought adaptions and fire adaptations has sometimes been contentious (Bradshaw et al. 2011, Keeley et al. 2011). We are not aware of studies raising the possibility of evolutionary trade-offs that could be beneficial under drought but detrimental under fire. However, leaf senescence during dry periods could be one such effect, as it temporally increases crown flammability.

Tree morphology. - Tree morphology is also linked with the fire regime as it influences the likelihood of experiencing a crown fire and it additionally affects the degree of thermal insulation for buds and leaves within the canopy. Height of the crown base and canopy bulk density (CBD) are essential traits underlying the probability of a crown fire (Agee 1998, Climent et al. 2004, Fernandes et al. 2008). The height of the crown base affects the likelihood that the flames within a surface fire will reach the crown and, consequently, affects the likelihood for a surface fire to become a canopy fire. That is, a self-pruning tall tree increases its likelihood to survive a fire by maximizing the distance between the flames and the foliage and growing meristems (Peterson 1985, Schwilk 2003, Balfour and Midgley 2006, Fernandes and Rigolot 2007, Clarke et al. 2013), and this capacity to self regulate the "fuel ladder" is considered to be a niche construction mechanism (that is, a modification of the environment with evolutionary consequences; Schwilk 2003). This effect is likely to play a smaller role with shorter trees, as they can be totally scorched by radiation during surface fires and die (as a rule of thumb, the height of crown scorch is considered equal to six times the flame length (van Wagner 1973). In addition to species attributes, site characteristics, including fertility and stand age, additionally contribute to variability in crown base height.

CBD influences fire spread across crowns (van Wagner 1977a, 1993, Alexander 1988). More specifically, 
CBD is affected by the length, porosity, and density of the canopy (Van Wagner 1977b, Alexander 1988, Michaletz and Johnson 2007), which jointly define heat dissipation efficiency and potential for fire propagation (Van Wagner 1977b, Alexander 1988, Michaletz and Johnson 2007). CBD is particularly problematic to measure, as it requires a very detailed harvesting, and data is only available for a handful of species. Currently, heuristic allometric equations are being used to determine CBD, but their validity has not been widely assessed across broad ranges of species (Keane et al. 2005, Keane 2015).

Apart from diminishing the probability of a crown fire, trees also show traits that reduce heat damage to the crown, with marked differences across tree species. Such crown protection arises from differences in the surface to volume ratio of leaves, and in the capacity for thermal insulation of buds, rather than differences in heat tolerance of meristems per se (Anderson 1970, Fernandes and Rego 1998). A high surface to volume ratio allows for high heat energy exchange between the leaf and the surrounding air, facilitating their ignition. Additionally, for a given level of tree scorch, different species show different survival rates, as we will discuss in detail later on.

An unresolved issue is to what extent plant traits affect overall flammability. Leaf flammability traits have been reported to be a poor indicator of overall plant flammability in different shrubs and rankings of flammability may be reversed from the leaf to the plant scale (Madrigal et al. 2011, Fernandes and Cruz 2012). This is because the load and three-dimensional distribution of the fuel particles is more important than the particles per se. However, recent fire behavior models obtained significant increases in goodness of fit when leaf traits were included in addition to fuel loads and structures (Zylstra et al. 2016). In fact, Zylstra et al. argued that floristic composition is a more important driver of fire intensity and severity than fuel load and structure. However, an important debate still remains on how flammability scales up from leaves to individual plants and the stand.

Bark.-Bark is a tree protection mechanism that is considered to have evolved under regimes characterized by low-intensity surface fires and, more specifically, for fires that do not cause death-inducing crown scorch. This would explain why crown-fire conifers such as P. halepensis, show modest bark thickness (relative to other European pine species [Fernandes et al. 2008]) but invest significant resources into serotinous cones (Santos-del-Blanco et al. 2014). Deeper bark can enhance protection and ensure that sprouters do not suffer topkill after crown fires. Bark serves to insulate the cambium, vascular system and meristems from lethal temperatures (Pausas 2015a). However, it is still being discussed whether bark traits influencing fire resistance, such as total thickness, proportion of inner bark or density and porosity, have actually evolved in response to fire, to increase water and carbohydrate storage, or in response to other environmental drivers (Rosell 2016).
Bark thickness is currently regarded as the most important property influencing its capacity for thermal insulation, but relative proportion of inner vs. outer bark, density, water content, structure and texture also play important roles (Vines 1968, Pinard and Huffman 1997, van Mantgem and Schwartz 2003, VanderWeide and Hartnett 2011, Brando et al. 2012, Wesolowski et al. 2014).

Bark thickness shows a strong positive linear correlation with stem diameter, and the latter may be used as a predictor of the susceptibility to fire-induced stem damage and mortality (Ryan and Reinhardt 1988, Hengst and Dawson 1994, Dickinson and Johnson 2001, van Mantgem and Schwartz 2003). In fact, fire-induced mortality is inversely correlated with increased diameter and bark thickness (Kolstrom and Kellomaki 1993, Pinard and Huffman 1997, Linder et al. 1998, Wirth et al. 1999, Ordóñez et al. 2005, Sidoroff et al. 2007, Fernandes et al. 2008). Across species, the time it takes to heat the cambium to lethal temperatures is exponentially correlated with tree diameter and bark thickness, and thermal resistance is roughly proportional to the square of bark thickness (Hare 1965, Dickinson 2002, Brando et al. 2012, Wesolowski et al. 2014).

The inner bark often shows significantly higher density and moisture content than the corky outer bark and, consequently, leads to in non-uniform thermal diffusivity across the bark (van Mantgem and Schwartz 2003, Rosell 2016). That is, the inner bark provides a disproportionately larger protection (by cross section area) than the outer bark. van Mantgem and Schwartz (2003) found that the proportion of inner bark to total bark thickness tends to decrease with increasing stem size and, therefore it is relatively higher in small trees. Consequently, young trees might show greater resistance to fire induced stem mortality than expected solely by their diameter.

Secondary contributors such as structural properties (e.g., fissures, surface roughness), moisture content and bark density are currently being discussed. Fibrous outer bark is more flammable and often associated with higher outer bark temperatures during fire (Hengst and Dawson 1994, Pinard and Huffman 1997) as well as greater cambium heating (Lawes et al. 2011, Wesolowski et al. 2014). Smooth barks are sometimes considered more effective insulators than rough barks due to their homogeneity (Hengst and Dawson 1994, Wesolowski et al. 2014), but air in fissures of heterogeneous barks could also be beneficial for heat dissipation (Dickinson and Johnson 2001, Barlow et al. 2003).

Water content in the bark can have both positive and negative effects on survival rate (Vines 1968, Dickinson and Johnson 2001, Bova and Dickinson 2005, Brando et al. 2012, Wesolowski et al. 2014). Water reduces stem heating through latent heat of vaporization (Brando et al. 2012), but water also has a high heat capacity, which could lead to prolonged exposure to high temperatures, potentially contributing to damaging the cambium (Lawes et al. 2011, VanderWeide and Hartnett 2011). High bark density additionally increases heat 
resistance by reducing the thermal diffusivity of the bark (Lawes et al. 2011, Brando et al. 2012).

Roots.-Although soil surface temperatures can reach $1,000^{\circ} \mathrm{C}$ or more during a high-intensity fire, heat release is usually limited to the uppermost $5-15 \mathrm{~cm}$, because most soils have very poor thermal conductivity (Choczynska and Johnson 2009), particularly in the dry summer months. Temperature distribution in the soil surface is very patchy, resulting in fires burning severely and resulting in areas nearly sterile while others remain practically unburned. Forest fires in Mediterranean ecosystems, that are typically not affected by ground fires, affect the soil ecosystem only locally where a high fuel accumulation (e.g., a recently fallen tree) causes very high temperatures in the top $30-40 \mathrm{~cm}$ of the soil profile (Hartford and Frandsen 1992). The rest of the soil will stay relatively unaffected and capable of supporting seedlings or sprouts that start growing right after the fire (Martínez de Aragón et al. 2012).

The role of fire in damaging roots has received only limited attention (Michaletz and Johnson 2008), and it is currently thought that root damage is limited to cases of extended soil heating, which typically occurs during ground fires (Hartford and Frandsen 1992, Dickinson and Johnson 2001, Stephens and Finney 2002, Varner et al. 2007, Choczynska and Johnson 2009), a fire type that is rare in Mediterranean environments. Roots act as major organs of storage and their main role in modulating the survival after a fire may thus come from providing the resources required for resprouting, in those species showing this capacity (Clarke et al. 2013).

\section{Physiological processes}

The key purpose of structural adaptations is the protection of essential physiological functions that determine tree survival. The cambium, phloem, and xylem are the tissues responsible for the secondary growth, downward transport of photosynthates, and upward transport of water and nutrients, respectively. Heat conducted through the bark can damage these tissues once the depth of necrosis exceeds bark thickness (Bova and Dickinson 2005). Understanding how heat damages plant tissues is crucial for understanding fire induced tree mortality (Dickinson and Johnson 2001), and several different mechanisms are thought to be related to subsequent tree mortality (Michaletz et al. 2012, Wesolowski et al. 2014).

The most important processes explaining fire-induced tree death, at least in non-sprouting trees that develop a bark thicker than about $2 \mathrm{~cm}$, are crown scorch and consumption (van Wagner 1973, Sieg et al. 2006). However, substantial mortality could occur in the months after the fire and cambium and phloem necrosis, due to charring (Dickinson and Johnson 2001). Necrosis is the result of protein denaturation caused by heat stress (Rosenberg et al. 1971) and, in the vascular cambium and phloem, occurs almost instantaneously when cells are heated to $60^{\circ} \mathrm{C}$ or higher, as well as during prolonged exposures to temperatures over $50^{\circ} \mathrm{C}$ (Hare 1965, Gill and Ashton 1968, Hartford and Frandsen 1992, Gutsell and Johnson 1996, Dickinson and Johnson 2004, Jones et al. 2006, Michaletz and Johnson 2007). During cambium and phloem necrosis, the stem becomes girdled and, when extensive, it can prevent photosynthate transport, which then leads to a depletion of carbohydrate reserves thus causing eventual plant death (Kramer and Kozlowski 1960, Dickinson and Johnson 2001, Michaletz and Johnson 2007).

Trees store substantial amounts of reserves in the form of non-structural carbohydrates. Therefore, stem girdled trees can survive for a long period of time, up to years or decades (Kramer and Kozlowski 1960, Michaletz and Johnson 2008, Midgley et al. 2011, Michaletz et al. 2012). However, post-fire tree mortality has been documented to occur within weeks or months (Ducrey et al. 1996, Michaletz et al. 2012), which suggests that other mechanisms might be involved.

While much less explored, the possibility of heatplume-induced losses in hydraulic conductivity has long been recognized (Rundel 1973, Ducrey et al. 1996, Balfour and Midgley 2006). However, only recent studies formally demonstrated that fires could induce catastrophic xylem failure (Kavanagh et al. 2010, Michaletz et al. 2012, West et al. 2016). This occurs via air seeding cavitation after the extreme vapor pressure deficits created by the heat plume, but also via deformation of cell walls in water conducting vessels or tracheids after heating cells to temperatures over $60^{\circ} \mathrm{C}$.

Consequently, forest fires lead to substantial reductions in sapwood area and sap flux density (Ducrey et al. 1996, Schoonenberg et al. 2003, Balfour and Midgley 2006, Kavanagh et al. 2010). Such reduced conductivity subsequently leads to desiccation of other tree parts such as the crown (Tyree and Zimmerman 2002), with the critical thresholds being $50 \%$ of hydraulic conductivity losses for conifers (Brodribb and Cochard 2009) and 80$88 \%$ for hardwoods (Resco et al. 2009, Urli et al. 2014). Once these critical thresholds are reached, the tree is unable to recover its conductive tissue and new growth or resprouting will be necessary for survival.

It is important to remember that fire is not a binary variable (e.g., burned/unburned), and that its effects on tree mortality will depend upon the intensity and the severity of the burn. Low to intermediate fire intensities, either in planned or unplanned fires, could also have positive effects for tree growth and hydraulic status. This is because low/intermediate-intensity fires, more common in mountainous regions of the Mediterranean basin (Touchan et al. 2012, Slimani et al. 2014), will not lead to crown scorch or hydraulic or cambium damage in mature trees with thick bark but may reduce competition by killing smaller individuals or understory vegetation. In these circumstances, fire may act as a thinning operation that reduces competition and, subsequently, temporarily improves the stand's water status (Alfaro-Sánchez et al. 
2016, Resco de Dios 2016). Perhaps the main challenge for predictions of fire damage therefore does not lie in modeling tree parameters as such, but in understanding microsite variations in fire intensity. In fact, post-fire tree mortality models often consider the degree of crown scorch, a variable related with surface fire intensity.

Current stand-level models of mortality show a reasonable degree of accuracy and are mostly based upon the degree of either crown (e.g., buds) scorch and consumption or cambium mortality and ignore any potential hydraulic limitations (Sieg et al. 2006, González et al. 2007). The relative contribution of hydraulic failure to mortality is not well quantified and, because crown and cambium mortality will likely be correlated with hydraulic damage, any potential contribution of hydraulics may remain hidden. It is important to decouple the functional role of hydraulics from that of crown and cambium damage, especially when modeling vegetation response to novel environmental conditions (e.g., in Dynamic Global Vegetation Models).

Moreover, considering recent reports of increased post-fire mortality after protracted droughts (van Mantgem et al. 2013), and the seemingly overwhelming effect of drought on plant hydraulics (Rowland et al. 2015), a deeper exploration of the links between hydraulics, drought stress and fire survival is needed. To illustrate this link we crossed published records of vulnerability to drought-induced cavitation in conifers (Choat et al. 2012) with records on fire tolerance from the USDA Plants database and with records on resistance to crown kill by fire in European pines (Fernandes et al. 2008) and, surprisingly, obtained a negative correlation (Fig. 5), suggesting that trees that are more resistant to crown kill are less resistant to embolism (database available online). ${ }^{8}$ This response could be explained by longterm standing ecological theories, such as the C-S-R (competitors-stress tolerators-ruderals) triangle theory, which predicts trade-offs between stress and disturbance tolerance (Grime 1977). According to this theory, plants are able to cope with either high levels of stress or of disturbance, but they are not able to cope high levels of both stress and disturbance. Understanding the tradeoffs between drought and fire resistances, and a deeper understanding of the links between plant hydraulics and survival after fire are priorities for future research.

\section{Resistance to fire induced mortality through resprouting}

Resprouting is often regarded as an ancestral condition in angiosperms and lack of resprouting a posterior specialized development (Wells 1969, Bond and Midgley 2003). Consequently, resprouting is a major mechanism contributing to the resistance of Mediterranean forests to fires. In fact, from the point of view of vegetation dynamics, resprouting and, in particular, crown resprouting, are perhaps the most efficient mechanism

\footnotetext{
${ }^{8}$ www.plants.usda.gov
}
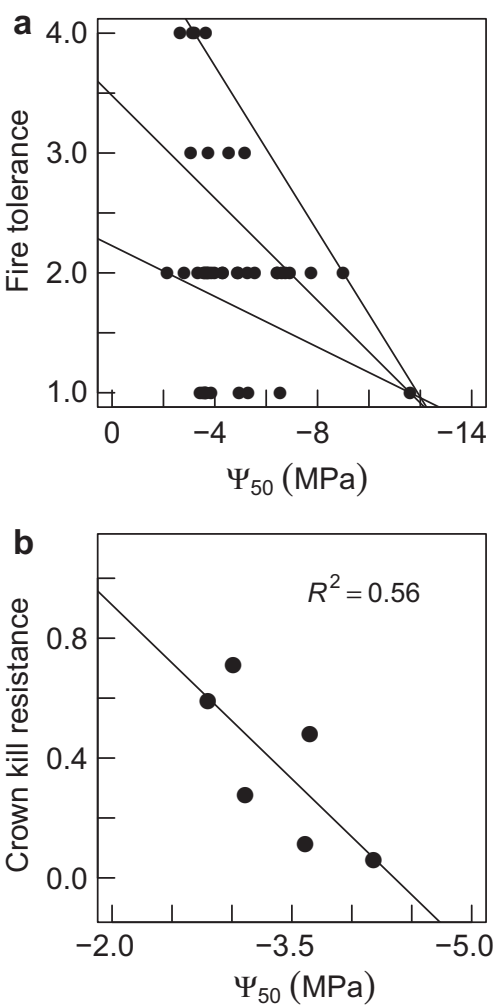

FIG. 5. (A) Embolism resistance and fire tolerance are inversely correlated in conifers. We obtained fire tolerance data from the USDA plants database (plants.usda.gov; 1, none; 2, low; 3, medium; 4, high) and additionally digitized data from resistance in European pines to (B) crown kill from Fernandes et al. (2008), and combined it with data from Choat et al. (2012) on embolism resistance. The USDA database provides a value on "the relative ability to resprout, regrow, or reestablish from residual seed after a fire," and there are four possible levels (none, low, medium, high). Resistance to crown kill reflects bud tolerance to heating (inferred from bud width), bud shielding from heat provided by needles, and time-temperature thresholds for needle and bud necrosis (Fernandes et al. 2008). $\Psi_{50}$ is an indicator of embolism resistance as it indicates the pressure potential where $50 \%$ of the hydraulic conductivity is lost, with more negative values indicating higher embolism resistance. The lines in panel $\mathrm{A}$ indicate the result of fitting quantile regression $(0.25,0.75$, and 0.90 quantiles, respectively, from bottom to top), and in panel B of simple regression. All lines are significant at $P<0.08$.

of resistance in environments characterized by high frequency and high-intensity crown fires. However, it is unknown for how long this mechanism can continue to operate under future environmental conditions. There are reports from the southern Alps of decreases in resprouting vigor or even a lack of resprouting in beech (Fagus sylvatica) trees that were growing on sunny, south-facing slopes (Ascoli et al. 2013); although the underlying mechanism has so far not been resolved, it is likely that the degree of stress experienced prior to the fire played an important role (van Mantgem et al. 2013), as will be discussed in more detail below. Considering widespread increases in tree defoliation after decreased 
water availability (Carnicer et al. 2011), and widespread occurrence of processes decreasing the health of resprouters, such as the oak decline (Brasier 1996, Gil-Pelegrín et al. 2008), it is possible that many resprouter species are approaching the limit of their resprouting capacity, a process we will refer to as the "resprout exhaustion syndrome." This hypothesis is further backed up by reports of increasing losses of resilience in resprouter-dominated ecosystems as stress increases over time (Díaz-Delgado et al. 2002). Several exhaustive reviews are available on the drivers of resprouting after different disturbances (Clarke et al. 2013, Pausas et al. 2015, Zeppel et al. 2015), but the question of what stress conditions weaken resprouters to the point that they lose their sprouting capacity deserves further attention.

Simplifying, resprouting ability depends upon a successful protection of viable bud bank or bud forming meristematic tissues (i.e., vascular cambium), the storage of nonstructural carbohydrates to support the regrowth until the photosynthetic capacity is recovered (Chapin et al. 1990), and the availability of water and nutrients (Peguero and Espelta 2011). Bud limitations have been reported in experimental studies after exposing plants to multiple rounds of burning within a short time frame (Paula and Ojeda 2009), with buds being either consumed by fire or used to resprout, ultimately leading to a lack of resprouting buds in basal resprouters. Whether similar bud limitation could occur in the field is more dubious, as buds will often have time to regenerate during growth in the interval between fires.

Lack of carbohydrates has traditionally been regarded as the main limitation to resprouting (Pate et al. 1990, Bowen and Pate 1993). As drought stress increases and photosynthesis declines, trees rely upon stored reserves for survival. Protracted drought could thus decrease carbohydrate reserves, potentially limiting resprouting capacity, but the availability of non-structural carbohydrates only seldom declines beyond critical thresholds even during extreme droughts (Korner 2003, Duan et al. 2014). However, if trees need to rely on stored carbohydrates for resprouting, subsequent fire events, triggering resprouting at high frequency, could eventually lead to carbohydrate depletion (Bowen and Pate 1993). In contrast, other studies reported that the concentrations of non-structural carbohydrates are not related to resprouting vigor (Richards and Caldwell 1985, Erdmann et al. 1993, Cruz et al. 2003), and the role of storage organs concerning remobilization of other nutrients (e.g., $\mathrm{N}$ and P) is also not clear (Clarke et al. 2013).

An alternative hypothesis on the drivers/limitations of resprouting is water availability, as resprouting cannot occur under extreme water stress. There are reports of resprouting exhaustion in Mediterranean shrubs under water (but not carbohydrate) scarcity (Cruz and Moreno 2001) and even death of resprouters has been documented under acute water stress (Fensham et al. 2009). Moreover, drought acts as a weakening agent that increases the probability of attacks by pests and pathogens, which would substantially hamper tree resprouting (Oliva et al. 2014). Additionally, tree age could diminish resprouting vigor, particularly in those with older and larger stems, due to the increasing costs of respiratory maintenance with size and to hormonal changes (Juvany et al. 2015, Munné-Bosch 2015). This lack of consensus on the limits to resprouting is hindering efforts toward modeling postfire vegetation dynamics. Understanding the limits to resprouting and the ultimate process leading to resprout exhaustion will thus be necessary for predictions of the probability of resprouting success under projected future climate conditions.

Another factor potentially impacting the resilience provided by resprouters lies in their regeneration constraints. In fact, most resprouting species have relatively heavy seeds that are bird dispersed and, consequently, dispersal distances are relatively short (Gómez 2003). This represents an important limitation to the recovery of these populations as colonization to new spaces will be limited. Additionally, herbivory of emerged seedlings represents an important bottleneck, as we will discuss later on.

\section{Summary and outlook}

There is a large body of knowledge on the adaptations to survive a fire in seeders and resprouters and the mechanisms are different enough that the two functional groups should be treated separately. Survival in seeders largely depends on spatial variations in fire spread and intensity, leading to variations in the degree of crown defoliation, with feedbacks between plant traits, stand flammability and fire behavior playing potentially important yet still unknown roles. Resprouting is the primary mechanism enhancing fire survival and, while modeling of fire survival in seeders has been relatively successful from the degree of crown defoliation (and other parameters), modeling resprouting remains a major challenge to understand post-fire responses. Additionally, understanding to what extent pre-fire drought affects post-fire survival remains contentious. Some studies have reported that pre-fire drought enhances fire severity in conifer forests, but the mechanism remains elusive since fire intensity appears to be the major mechanism explaining mortality. Pre-fire drought might play a secondary role in determining survival of seeders by pre-weakening individuals, but it is unclear why it should play a major role in explaining the bulk of survival. Additional experiments should also clarify to what extent fire and drought are antagonistic adaptations. Pre-fire drought acting upon resprouters, however, might have an overwhelming effect as it could lead to both xylem failure and depletion of carbohydrate levels, which in turn would seriously compromise post-level resprouting. Additional knowledge gaps are given in Table 1.

\section{Resilience to Fire at Population Level}

Tree mortality occurs when individuals succumb to fire. A high-intensity fire is more likely to reduce survival 
rates, thus resulting in widespread mortality. In the case of stand-replacing fires in non-sprouting forests, population resilience depends on the ability to recover through the recruitment of new individuals (Fig. 3, Table 1). Successful recruitment of individuals is reliant upon the amount of post-fire viable seeds available and subsequent seed germination, and on seedling establishment and survival. Mycorrhizal networks, when present, will favor seedling establishment.

\section{Propagule availability}

The availability and quantity of viable seeds in a burned area is a major requirement for successful population recovery, and the source for recruitment can originate from on-site or off-site seed banks (Resco de Dios et al. 2007, Martín-Alcón et al. 2015). Propagule availability is thus affected by different aspects of the fire regime including fire intensity and severity (for on-site seed banks) or burned size patch and shape (for off-site seed banks).

On-site recruitment includes soil or aerial seed banks that have escaped heat damage due to the insulation properties of soil or of fruits and cones, respectively (Noble and Slatyer 1980, Lloret 1998). Serotiny, the delayed opening of cones or fruits in response to heat, is a rare feature among EU Mediterranean species, and within trees, it is present in only two pine species, i.e., $P$. halepensis and some populations of $P$. pinaster (Tapias et al. 2004, Gil et al. 2009) although, strictly speaking, these are semi-serotinous species as cones also open regularly in the absence of fire. Fire directly enhances the opening of serotinous cones resulting in a simultaneous release of large numbers of seeds under conditions of no competition and high radiation (Keeley and Fotheringham 2000). Forest management, by regulating tree density, plays an additional role in determining seed availability as strong competition inhibits seed production. Consequently, thinning may enhance seed release (as is often done in regeneration techniques including shelterwood systems; Matthews 1991).

The degree to which fire could be a selective agent has been the subject of a long ongoing debate, and serotiny could be an example of a trait evolved as a result of crown fires (Keeley et al. 2011). For instance, serotiny is under genetic control in $P$. pinaster, and it is only present in those populations that have historically experienced recurrent high-intensity fires (Gil et al. 2009). Additional traits, such as smoke-induced (Tormo et al. 2014) or heat-induced (Céspedes et al. 2012, Chamorro et al. 2016) germination, are examples of potential reproductive traits selected under high fire frequencies, but they will not be dealt with here as they are uncommon in trees. Nonetheless, the degree to which these traits are truly fire adaptations remains contentious. Smoke-induced germination, for instance, is also present in species that are seldom exposed to fire (Flematti et al. 2004).

One of the main constraints on propagule availability is seed predation. In some extreme cases, $>80 \%$ of all seeds in different stands of Pinus halepensis were predated within the first 6 months after the fire, ultimately leading to regeneration failure at that site (Pausas et al. 2004). Seed predators are difficult to model as they comprise a wide variety of species (including birds, rodents and ants) and vary strongly with time and space. Consequently, seed predation acts as another major factor controlling propagule availability that can limit local recruitment and have cascading effects post-fire plant distribution.

For Mediterranean seeder tree species lacking seed banks, seed originating from surviving trees in the marginal boundaries of the fire or in unburned patches within the fire perimeter may be the only alternative seed source. The spread of propagules and recolonization of the burned area are distance-restricted by the seed dispersal ability and by the form, sizes, extent and spatial configuration of burned and unburned patches (Ordóñez et al. 2005, Vilà-Cabrera et al. 2011, Martín-Alcón and Coll 2016). Isolated patches of mature trees exhibit enhanced seed production due to reduced competition (Ordoñez et al. 2006). However, dispersal is limited in pines to distances up to $100 \mathrm{~m}$, indicating that, for species other than the few that are serotinous, propagule numbers for postfire regeneration will generally be limiting in large fires.

Propagule availability is, at least to some degree, decoupled from the intensity of drought immediately after the fire. This is because seed banks do not depend solely on current year propagules. On the contrary, seeds accumulate for a number of years prior to the fire and, consequently, water availability on the year of the fire would not have a major effect on seed availability. Only if extreme water scarcity limits seed production for a number of years, a significant impact on propagule availability could be expected.

\section{Propagule establishment}

Successful propagule establishment requires the concurrence of different conditions and processes, including adequate moisture and nutrient supply, breakage of dormancy in some instances, microclimatic conditions favorable to the development of that species, no herbivory, and establishing symbiotic relationships with mycorrhizal fungi (in most Mediterranean woody species). Additionally, establishment requires fire return intervals that are long enough to allow seedlings to become established and to become mature individuals, so new seeds may be available when the following fire occurs. Predicting actual establishment rates therefore remains a complex challenge, particularly if we are also trying to predict the spatial arrangement of the upcoming population. Requirements for species may change markedly from germination to survival and keep developing through ontogeny (Quero et al. 2008, Resco de Dios et al. 2014). Moreover, topographic and climatic variation at landscape scale and, additionally, on resource distribution and herbivory at fine, microsite scales add additional complexity to the process. 
Here we distill this complexity by focusing only on three interconnected hypotheses that have gained support over the last years to explain post-fire establishment (once propagules are available). We choose to focus on these three hypotheses as they indicate a hierarchy of mechanisms, with different processes becoming important at different periods. We only discuss hypotheses specific to post-fire establishment, as additional processes generally affecting establishment (such as herbivory or pests and pathogens, to name a few) have been addressed elsewhere (Crawley 1996, Wilkinson and Sherratt 2016).

The first hypothesis is that post-fire plant establishment depends on the existence of "windows of opportunity” (Quintana et al. 2004, García et al. 2016). Germination and survival do not occur at the same rate at any given time of the year but vary seasonally. Mediterranean summers tend to be dry and are commonly followed by significant rainfall in September or October, which provides a window of opportunity for new plants to recruit and develop an extensive root system before the onset of cold winter temperatures. There is a multiplicity of factors that could affect the frequency or duration of such windows of opportunity, including intra-annual climatic variation, amount of litter (from scorched leaves that will fall after the fire), topographic and edaphic factors, and herbivore densities, to name a few (Trabaud et al. 1985, Pausas et al. 2003, Madrigal et al. 2005, García et al. 2016).

Windows of opportunity occur temporally, but also spatially, into what are known as "safe sites," which are microsites that could offer protection for seedlings, such as under-canopy spaces that provide higher winter temperatures and protect against winter frosts, for example (Lamont et al. 1993).

A second hypothesis is the "early-to-rise" hypothesis, which predicts that seedling survival is primarily driven by the establishment date, such that seedlings emerging early within a window of opportunity have a higher probability of success than those emerging at a later stage. The underlying rationale is that the first seeds to appear have more time to develop and face the upcoming unfavorable seasons (cold winters or dry summers) with a bigger root system that allows for more extensive soil exploration, and longer and thicker hypocotyl or stems that protect against damaging temperatures (Woods et al. 2014). This hypothesis contrasts with the safe site hypothesis, in that it postulates that the spatial arrangement of seedlings does not ultimately drive recruitment, but that the date of emergence within a window of opportunity plays a crucial role (de Luis et al. 2008).

Related to the windows of opportunity hypothesis is the "event-dependent" hypothesis, which states that post-fire plant recruitment is driven by the environmental conditions immediately post-fire (Bond and van Wilgen 1996, Moreno et al. 2011). If, for instance, an intense drought (too intense to allow for seedling establishment) follows a wildfire, the combination of events may create a legacy such that plant cover may remain very sparse for a longer time. Therefore, the eventdependent hypothesis states that the conditions at the time of the fire create a long-term legacy for the posterior dynamics of the community.

The existence of such legacies may be appreciated in Fig. 6 where, up to eight years after the fire, the composition of the community was dependent upon establishment success during the first year. Indeed, Fig. 6 suggests that, while safe sites may exist, their influence at the plot scale would be limited and exert small impacts on the subsequent eight years after the fire. This is because seedling density in different years after the fire was linearly dependent on the number of germinants in the first year. The question then becomes, what drove initial plant establishment and initial plant density?

Different initial plant establishments have been observed at a given site, depending upon when the fire occurred, indicating a major effect of the environmental conditions immediately post-fire. For instance, Moreno et al. (2011) report that stand composition three years after fire could be explained by the precipitation in the season immediately after the fire. Therefore, differences in the environmental conditions of the first year after fire would create differences in initial establishment (variation in $x$-axis of Fig. 6), and this initial composition creates a legacy and survival in upcoming years is simply a fraction of that in initial years (resulting from herbivory, diseases, stress, or other processes). Competition and other density-dependent processes are additional important drivers of community dynamics, but their influence often starts at a later stage, after seedling establishment.

\section{Propagule survival}

Interactions between species physiology, herbivory, fire regime, climate, and site characteristics will determine the survival of the seedling population. Drought is often the major determinant of propagule survival, but its effects are mediated by species physiological traits. Protracted periods of water scarcity lead to catastrophic xylem failure and also to fatal depletions in carbohydrate reserves (carbon starvation; McDowell et al. 2008). Additionally, the downward flow of photosynthates through the phloem may be impaired, particularly if high soil temperatures lead to stem girdling (Helgerson 1990). These three different processes should not be viewed as mutually exclusive but as interdependent (McDowell 2011). For instance, stomatal closure prevents runaway cavitation but also inhibits carbon assimilation. As drought advances, cuticular or residual water losses remain and continually consume the water stored in the stem capacitors until catastrophic thresholds are crossed (Resco et al. 2009, Blackman et al. 2016, Skelton et al. 2017). Concomitantly, respiration also continuously decreases carbohydrate levels during drought and, whereas carbon starvation is rare in adult plants, lack of reserves has been documented in seedlings (Pratt et al. 2014). Seedlings cannot recover from a drought 

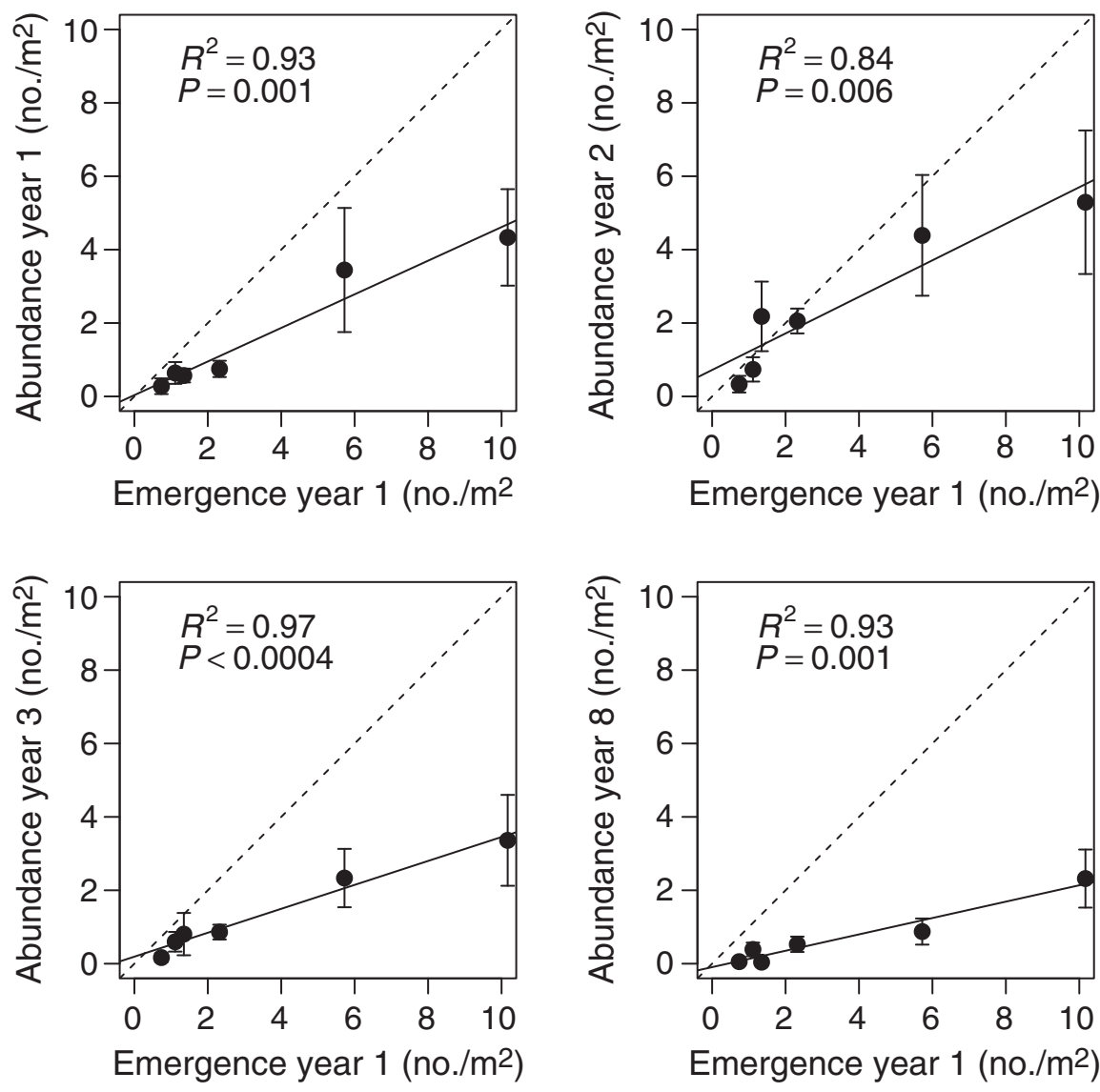

FIG. 6. Strong legacy effects of initial emergence on community dynamics. Data represents values (mean \pm SE) for six different shrub species in a Mediterranean shrubland after a fire. The dotted line is the 1:1 relationship and the solid line is the result of leastsquares fitting. Emergence in the first year after fire explained a significant portion of the variation in the abundance of the different species during the first, second, third, and eighth, respectively, year after a fire. Original data from de Luis et al. (2008).

after crossing a certain threshold of xylem hydraulic failure and also after depleting carbohydrate reserves to the point where demand exceeds supply (Pratt et al. 2014). Difficulties in measuring phloem flow prevent from generalizations on its overall role.

Survival in adult plants is often related to stomatal behavior such that anisohydric plants, with loose stomatal control, are considered more likely to suffer from catastrophic cavitation whereas isohydric plants, with stronger stomatal control, are considered to be more prone to carbon starvation (McDowell et al. 2008). However, such a simplifying scheme is likely to have limited predictive power of survival in post-fire regeneration: apart from stomatal behavior, additional traits affect the water and carbon balances of the plant, including root:shoot ratio (higher ratios potentially increasing water uptake), cuticular conductance and stem capacitance (as previously discussed), and drought deciduousness, where complete wilting would not be linked to mortality as the plant would be able to resprout. Post-fire seedlings will often be more vulnerable to drought than pre-fire adults because of lower root:shoot ratios, smaller carbohydrate reserves, and because their xylem may possibly be more vulnerable to cavitation (lignification in some species does not occur in their first years).

Herbivory raises an additional challenge for seedling survival because consumption of plant parts may jeopardize seedling survival (Sagra et al. 2017). Seedlings have a limited size, storage, and capacity for withstanding herbivory, particularly under dry conditions that already pre-weaken the seedlings (Moreno and Oechel 1991). The effects of herbivory on seedling survival depend upon some aspects of the fire regime. This is because high-intensity fires often reduce the number of resprouts and also delay the time of resprouting. In turn, resprouting later in the season has been linked with increased herbivory because plants that resprout asynchronously from the main flush (later in the season), are more readily attacked by herbivores (Moreno and Oechel 1991).

However, and contrary to conventional wisdom, postfire environments may sometimes provide conditions that are more favorable to plant establishment. This is because fire diminishes plant competition and it could, consequently, increase water availability. Parra and Moreno (2017) observed higher predawn water potentials (indicating higher availability of water in the rhizosphere) and 
growth rates in burned (seeder and resprouter) shrubs that had been exposed to a $45 \%$ reduction of rainfall, relative to unburned plants exposed to ambient rainfall. This observation is intriguing and deserves further exploration, as it would suggest that the bottleneck for postfire survival may lie in seedling germination and establishment, rather than in posterior survival. Additionally, this observation could imply that high severity fire may be a useful strategy to regenerate shrublands or forests, but this hypothesis is still tentative and additional observations would be required. However, the effects of post-fire drought on plant regeneration are also contingent upon the fire regime and, in particular, fire recurrence and intensity.

Different attributes of the fire regime are essential drivers of propagule survival. In particular, short fire intervals hinder plant regeneration because they do not allow for seed development and also because regular fire application leads to decreased resprouting vigor. Consequently, the effect of fire recurrence depends upon the regeneration mode and species. Oak seedlings are often able to resprout even at one year old and, although consecutive fires at such early ages are likely to also exhaust resprouting capacity, where such threshold exists has not yet been established. Semi-serotinous pine species such as Pinus halepenesis require intervals of 10 years or more produce viable seeds and, consequently, shorter fire return intervals will compromise viability. Fire at the seedling or sapling stages in non-serotinous pine species will likely lead to their local extinction because they will not regenerate and because their thin barks will not effectively provide cambium even from low-intensity surface fires.

\section{Mycorrhyzal networks}

Most woody species in Mediterranean forests are obligate ectomycorrhizal, meaning that they are not able to complete their life cycle without establishing a symbiotic relationship with ectomycorrhizal fungi (Smith and Read 2008). This makes the remaining mycorrhizal community a critical component of the legacy of a burned stand (Buscardo et al. 2011). A well developed, healthy, and diverse ectomycorrhizal network may assist propagules to germinate and grow, as the network of fungal hyphae will increase their access to water and nutrients (Simard et al. 2013).

Whether or not such a functional ectomycorrhizal network is present will be a function of the time elapsed since woody vegetation was present (Baar et al. 1999). This is because mycorrhizae depend upon plants as a carbon source and their protracted absence may lead to eventual depletion of the ectomycorrhizal community. For instance, the ectomycorrhizal community could be depleted if, for instance, colonizing annual herbaceous species become the prevailing vegetation form after a fire, because these species normally do not form ectomycorrhizae (Torrecillas et al. 2012). If the woody plant population takes too long to re-establish at the site, they might encounter a belowground "desert" devoid of ectomycorrhizal fungi hyphae. Propagules from tree species would then germinate and grow, but at much reduced rates. Consequently, trees may not be competitive, in comparison with the colonizing annuals (which rely on arbuscular mycorrhizae), and such competition may complicate tree establishment (Richard et al. 2009). In other words, the longer the time for tree establishment, the higher the difficulty for such establishment because the ectomycorrhizal community may suffer (Lankau et al. 2015). Presence or lack of a functional ectomycorrhizal community may thus be a stabilizing mechanism for either a prompt tree establishment, or for the establishment of a community of ruderal annual plants, respectively. Moreover, even low severity prescribed burning could have negative longlasting impacts on the ectomycorrhizal community (Taudière et al. 2017). However, currently only a limited number of studies have assessed fire effects on mycorrhizae, hindering synthesis at the time of writing, but available evidence indicates a negative effect of elevated fire recurrence (Taudière et al. 2017, Tomao et al. 2017).

\section{Summary and outlook}

After individuals have succumbed to fire, a number of processes affect the recovery of the population. Propagule availability will often be affected to a minor extent by current year drought, as seed banks accumulate over a number of years. However, drought in the autumn after the fire is the major bottleneck for the establishment and survival of seedlings, and initial plant establishment creates a "legacy" such that mid-term composition reflects establishment within the first year after fire. Current climate projections predict increases in the duration of the summer drought in the Mediterranean basin, but not decreases in autumn precipitation. Consequently, climate change per se would not exert a direct short-term negative effect on post-fire recruitment (although indirect negative forcing may still occur). However, because successful establishment depends on a series of processes at later life stages, increasing drought intensity under climate change may lead to weakened seedlings and saplings and potentially compromise regeneration. This is because the growing season would be shortened, as a result of decreased precipitation and increased temperatures (potentially increasing evapotranspiration), and may not allow seedlings and saplings to develop the anatomical, reproductive, or physiological adjustments necessary to survive drought in posterior years. Land "clearance" by fire could serve to diminish plant competition and increase soil water availability and, consequently, fire would enhance regrowth of new sprouts and the establishment of new seedlings, although additional data will be required to confirm this observation. Additional management actions may be performed in nearby stands, such as thinning to increase seed production and release and increasing off-site seed availability. Overall, interactions between fire regime, water availability, and propagules will 
determine population recovery. Additional interactions between plants and other organisms also play crucial roles. Most Mediterranean species are obligate mycorrhizal, but hyphae abundance is negatively affected by fire, especially under high recurrence. Herbivory and seed predation exert an additional control over recruitment. Additional unknowns are given in Table 1.

\section{State Transitions after Fire and Changes in Community Dominance}

\section{Short-term transitions}

Forests in the Mediterranean region of the EU are dominated by either pines or hardwoods (typically Quercus) in pure or mixed stands. Pines are obligate seeder species but hardwoods are facultative resprouters. This individual-level trait makes hardwood forests more resilient to state shifts after fire, while pine-dominated forest stands are more prone to shift to either oak forests or to shrublands (Fig. 3, Table 1) particularly under high fire recurrences (Baeza et al. 2007, Martín-Alcón and Coll 2016, Torres et al. 2016).

The vulnerability of pine stands to state transitions depends on some specific species traits and site features. A single-fire event has been observed to lead to a state shift in forests dominated by the montane P. nigra and P. sylvestris (Retana et al. 2002, Baeza et al. 2007, Martín-Alcón and Coll 2016) and others (Torres et al. 2016). P. nigra and P. sylvestris show late flowering and lack of serotinous cones (Tapias et al. 2004), and their seeds do not resist high temperatures (Lanner 1998, Habrouk et al. 1999). Thus, although these pine species might resist low severity surface fires (Fulé et al. 2008), they succumb under high severity defoliating fires (Tapias et al. 2004, Fernandes et al. 2008, Morales-Molino et al. 2016). Other pine species such as P. halepensis and $P$. pinea (Vallejo and Alloza 1998) are so-called "fireembracers" (sensu Pausas 2015b) and usually recover after a single fire event (although there are exceptions (Baeza et al. 2007). P. halepensis is usually able to recruit after a fire from the seeds stored in its semiserotinous cones and $P$. pinea shows high resistance to fire (Fernandes et al. 2008), along with seeds protected by thick cones and coats that can endure high temperatures (Escudero et al. 1999). However, state transitions are very likely when a second fire occurs before newly recruited pines have reached maturity (7-10 years for $P$. halepensis (Thanos and Daskalakou 2000).

Fire can enhance the establishment of oak species, provided oaks are present at sufficient densities in the understory before the fire, as oak recruitment is generally very low due to dispersal limitations. Torres et al. (2016) found that post-fire tree composition and dominance were highly predictable from pre-fire understory structure. They studied post-fire forest shifts in stands previously dominated by either non-serotinous populations of $P$. pinaster or by the resprouter $Q$. pyrenaica and documented the shift from Pinus-dominated to Quercus-dominated forest stands when pre-fire densities of $Q$. pyrenaica in the understory exceeded 200 stems/ ha. Similarly, pine-to-oak transitions occurring in the first 15 years after a high-severity crown fire have been documented by Martín-Alcón and Coll (2016). Non-serotinous stands dominated by Pinus nigra were replaced by Quercus faginea and Quercus cerrioides stands, when significant oak presence occurred in the understory before the fires (Retana et al. 2002).

However, when understory oaks are absent, post-fire change to a non-forested state likely occurs after trees have succumbed to fire and no seed sources are available (Baeza et al. 2007, Pausas et al. 2008), or in sites of poor quality (e.g., rocky, south-facing, steep slope) (MartínAlcón and Coll 2016).

The non-forested state may lead to lower soil fertility and higher erodibility (Karhu et al. 2015, Vieira et al. 2015). Losses in soil fertility after a fire may act as an additional feedback stabilizing state transitions toward a nonforest state. Forest fires generally increase the availability (mineralization) of $\mathrm{N}$ and $\mathrm{P}$, although the availability of other nutrients, such as $\mathrm{K}$ may decrease (Hinojosa et al. 2016). However, such change in nutrient availability may be transient because total concentrations decline and because burned soils are much more erosion prone, which fosters further nutrient losses (Pausas et al. 2008, Vieira et al. 2015). Moreover, even if the quantity of soil organic matter increases after a fire, its quality diminishes substantially, especially under high fire recurrence. Once a forestto-shrubland transition has occurred, the loss in soil organic matter quality and in fertility create a stabilizing feedback for the non-forest state (Mayor et al. 2016). This soil degradation is further enhanced by drought, as enzyme activity decreases with water scarcity and consequently decreases mineralization rates (Hinojosa et al. 2016).

\section{Long-term dynamics}

After a state transition has occurred, the crux lies in understanding whether the post-fire ecosystem will persist. Shrublands and forests could both be "stable states" (i.e., not transient within ecologically relevant time scales) for a given set of environmental conditions (Batllori et al. 2015, 2017). There are experimental indications that post-fire succession in shrublands remains delayed or stopped, a process termed arrested succession (Baeza et al. 2006, Acácio et al. 2009, Santana et al. 2010, Acácio and Holmgren 2014). However, verifying this hypothesis is challenging, as the time scale of available observations is relatively short with comparison to the longest-lived late-successional species.

The presence of a positive feedback is necessary to explain the existence of alternative stable states, following basic dynamical system theory (DeAngelis et al. 1986). The feedback between ecosystem type and soil fertility, that we previously described (Mayor et al. 2016), must thus be accompanied by a feedback between fire and 
vegetation composition, analogously to what has been vastly argued for tropical savanna/forest systems (Hoffmann et al. 2012). At a given site, we could encounter a "pyrophytic" vegetation state, that promotes recurrent fires and requires them for its maintenance, or a "pyrophobic" vegetation state, which is less flammable but does not persist in the presence of fires (Bond and Midgley 2012). For the Mediterranean basin, there is some evidence (but not conclusive) for the existence of such firevegetation feedbacks for shrubland and pine forests. Areas that have burned in the past are more likely to experience another fire in the future (Loepfe et al. 2010). Shrublands are pyrophytic, as shrubs are highly flammable, due to their low water content, high heat of combustion, fine fuel, and high amounts of standing dead biomass (De Luis et al. 2004, Baeza et al. 2006, 2011, Pausas and Moreira 2012). The most common shrub species (such as, e.g., Rosmarinus officinalis, Ulex spp., Cistus spp.; Erica spp.) will either accumulate large, fire-resistant, long-lasting seedbanks, or show capacity for vegetative propagation, which allows them to regenerate and spread very rapidly after a fire (Santana et al. 2012). Conversely, pine forests are less flammable, but they are prone to disappear after consecutive fires, as we described above. This connection between plant traits and regrowth is similar to what observed in other Mediterranean ecosystems (Odion et al. 2010) and could potentially lead to a feedback between floristic composition and fire occurrence. However, forests including resprouter hardwoods are less easily included in this framework, as they cannot be described as pyrophobic because of their high fire resistance. Regardless, potential links between species traits and fire behavior are far from resolved and different studies indicate that large wildfire activity is independent of land cover type (Nunes et al. 2005, Barros and Pereira 2014, Fernandes et al. 2016).

Climate change raises an additional challenge to the long-term stability of state changes. Although some oak forests are now becoming established in previously pinedominated stands, some of these species may be out of their climatic niche by the turn of the century. For instance, Torres et al. (2016) documented that Quercus pyrenaica is currently replacing Pinus pinaster after a stand-replacing fire, as previously noted. However, these authors also note a decrease in future habitat suitability due to climate change, and a virtual local extinction for Quercus pyrenaica is modelled using species distribution models (Ruiz-Labourdette et al. 2012). Moreover, these authors also note a minimal climate space reduction for the pine species. Consequently, replacement of pine stands by oak forests may only represent a transient stage and climate change may exert an additional forcing affecting long-term state changes.

\section{Forest management}

Forest management activities conducted before the fire may help prevent fire-induced deforestation through two different, yet interconnected, processes. First, forest management can serve to create vegetation structures with higher resistance and resilience to fire. In contrast, forest management can create landscapes that are less prone to the spread of high-intensity crown defoliating fires. Additionally, several management actions can be conducted after the fire to avoid post-fire degradation. A full review of these processes is beyond our current scope and at least some of these topics have been covered elsewhere (Keeley et al. 2012, Moreira et al. 2012, Scott et al. 2014) but there are a few points that are relevant here.

High severity forest fires in the Mediterranean occur mostly on either abandoned reforestations or in oldfields. Abandoned reforestations have had little or no intervention after original planting, which was often done at high densities and, consequently, most of these stands will show horizontal and vertical continuity of large fuel loads, which, in turn, can promote high-severity fires. Reforestations in Mediterranean Europe mostly (re-)introduced conifer species in lands that had been previously cleared for different purposes (Vadell et al. 2016). Reforestation was consequently devised as a restoration technique that would later favor the encroachment of more shade-demanding oak species (Vadell et al. 2016). Recent articles propose active intervention to accelerate the encroachment of resprouting trees by either decreasing pine cover where resprouters are already present in the understory, or by introducing resprouters where they are still absent (Granados et al. 2016, Villar-Salvador 2016). This is because, generally speaking, increasing functional diversity could be a means to enhance post-fire survival by increasing the diversity of traits and, in particular, introducing resprouters would favor post-fire recovery as resprouting is the major trait conferring individual resilience to fires. However, increasing functional diversity has been sometimes shown to increase water limitation and to decrease stand resistance to water stress (Grossiord et al. 2014). Furthermore, as fire severity has been related to pre-fire drought and resprouting vigor may diminish after severe water stress, forest interventions that diminish plant competition and ameliorate the water balance will be required to enhance survival, while diversification per se has sometimes been shown to have the negative effect of diminishing water availability. Additional research will be needed to clarify whether and how diversifying reforestations may serve to avoid fire induced deforestation.

\section{Summary and outlook}

It has been argued that Mediterranean forests are increasingly on the brink of collapse. Global change is fostering more frequent droughts, which have increasing impacts as a consequence of land abandonment and excessive tree density. Mediterranean forests have traditionally shown high resistance and resilience to forest fires, but post-fire state transitions may become increasingly frequent as the climatic pressure over these forests 
increases. There are cases where a single fire event may replace species with aerial seed banks and complex interactions between different ecosystem components arise. Whether such state changes are transient or stable remains under debate and determining the feedbacks that would lead to alternative stable states is still being elucidated. Forest management, through stand diversification, has the potential to increase forest resilience, but increased diversity of fire responses may not ameliorate the negative effects of water stress. Climatic change is emerging as a new player that may reduce the climatic space of certain forest species. Additional unknowns are given in Table 1.

\section{Outstanding KnOwledge Gaps}

In this review, we have proposed a conceptual model for the drivers of fire-induced deforestation in the Mediterranean region (Figs. 2, 3, and 7, Table 1), and examined current knowledge in each of the stages leading to a state transition. To conclude, we now highlight some additional elements that deserve further attention.

\section{Trade-offs in resistance to drought and fire}

Fires and drought necessarily co-occur, and the overarching view is that natural selection has led to solutions for both circumstances, such as resprouting (Bradshaw et al. 2011, Keeley et al. 2011) or heat induced seed germination (Troia and Laguna 2015), to name a couple.
However, we have shown how trade-offs could occur, for instance, during leaf senescence, which diminishes water requirements at the expense of increased flammability, or through embolism resistance, which was negatively correlated with crown and cambium resistance to fire (Figs. 4 and 5). Forest fires annually burn $<1 \%$ of the non-agricultural land of the European countries of the Mediterranean Region (Turco et al. 2016) but water scarcity acts regularly over the entire region (Shestakova et al. 2016). A stronger selective pressure thus exists now toward drought-resistant than toward fire-resistant traits and it is therefore expectable that, if a physiological trade-off must occur, such adaptations will prioritize drought survival to the detriment of fire survival. However, it is worth noting that especially the seeder pine trees originated at a time when fire occurrence was much more prevalent than today (Keeley 2012).

We hypothesize that pre- and post-fire droughts will exert different pressures upon seeding and resprouting. Pre-fire drought will be of a lesser importance in obligate seeders in the Mediterranean Region (relative to postfire drought), because fires in the area are typically stand-replacing crown fires, where foliar and bud scorch and combustion, along with cambium and phloem necrosis will be the main mechanisms inducing mortality. However, pre-fire drought could weaken resprouter trees, increase their susceptibility to pathogens and pests and, potentially, exhaust their resprouting capacity. We therefore expect post-fire drought to be most important for deforestation in seeder-dominated areas, where seed

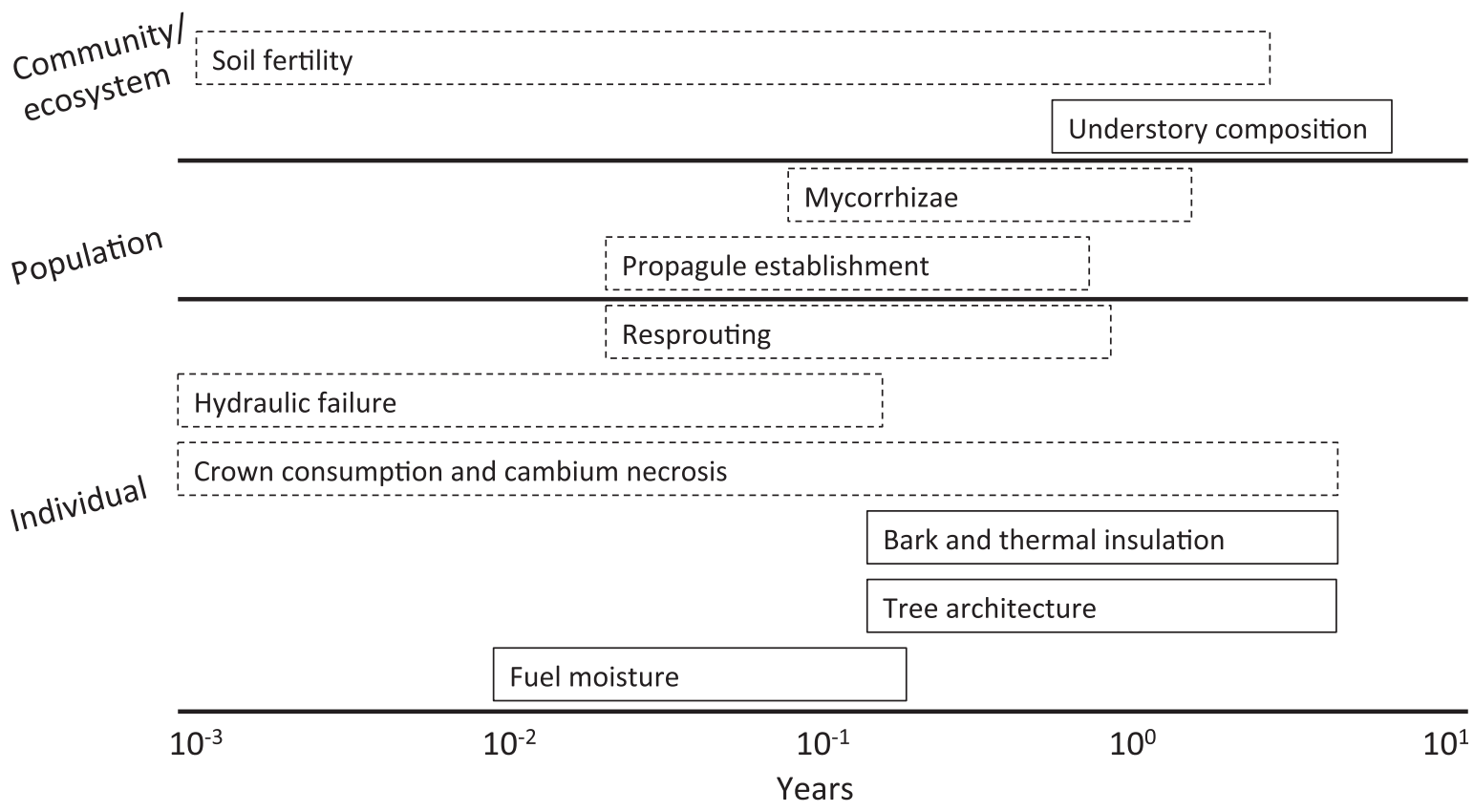

FIG. 7. Summary of processes involved in post-fire state transitions and the spatial and temporal scales over which they occur. These processes may occur before the fire (continuous line) or after the fire (dashed line) and determine the survival (resistance) of individuals, the persistence (resilience) of the population if individuals succumb, and whether the community transition is toward a different forest state or toward a non-forest state after the if the population fails to recover. 
establishment is strongly dependent upon germination and recruitment immediately post-fire, whereas pre-fire drought would be most important in post-fire deforestation in resprouter-dominated areas, due to the resprout exhaustion syndrome. Moreover, serotinous species form an aerial seed bank over many years, which further decouples seed production from pre-fire stress.

\section{Novel fire environments}

As a consequence of global change, we are seeing changes in the fire regime such that areas traditionally experiencing surface fires are now experiencing standreplacing crown fires. This is the case of mid-mountain areas up to $1,200 \mathrm{~m}$, where surface fires frequently occurred during the Holocene. The seeder species present in these forests are often fire-tolerant conifer species with thick barks (e.g., Pinus nigra, Cedrus atlantica; Touchan et al. 2012, Slimani et al. 2014). However we are now seeing stand-replacing crown fires as a new phenomenon starting two to three decades ago (Pausas et al. 2008, Torres et al. 2016). This has the potential to create major shifts in community composition, with transitions to non-conifer species in large wildland fires.

Another recent consequence of global change and firedrought interactions is the emergence of novel flammable ecosystems. Fire in high altitude mountains $(>1,300 \mathrm{~m})$ has in the recent past been negligible, although paleological records indicate the possibility of recurrent fires even in Pinus uncinata forests at 1,800 $\mathrm{m}$ above sea level in the Pyrenees during warm climate intervals (Gil-Romera et al. 2014). However, models of fire occurrence based on changes in fire weather are warning of the potential occurrence of wildfires in the high mountain conifer forests of the European Alps (de Angelis et al. 2015). Observational records from the Pyrenees show that the first fires in Pinus uncinata forests over the last millennia have occurred in the last five years (Cardil et al. 2016). The onset of novel flammable ecosystems is particularly worrisome because they occur in ecosystems dominated by species that are poorly adapted to fire. Indeed, comparisons of fire resistance across European pines have revealed $P$. uncinata as the least fire-resistant pine species (Fernandes et al. 2008). Losses of $P$. uncinata forests at the timberline is another example of how fire could lead to deforestation, as no other tree species currently grows at the timberline in the Pyrenees, and similar processes could occur with $P$. mugo in the European Alps.

\section{Alternative stable states and fire-vegetation feedbacks}

Understanding whether the transitions from a forested to a non-forested state will be stable or transient remains a major challenge, as previously noted. As we write (29 March 2017), the words "alternative stable state* Mediterranean fire" led to only four entries in the database Scopus (and six in Web of Science), and to 20 entries for the words "fire vegetation feedback*
Mediterranean," indicating an overall lack of studies on this issue. Given the long-term nature of ecological dynamics, current knowledge on long-term processes and on alternative stable states originates mostly from either chronosequences or from modeling studies. Chronosequences follow a space-by-time substitution approach, which has been shown to be problematic due to differences in initial conditions and other site idiosyncrasies (Walker et al. 2010). Modeling approaches provide a useful alternative but are limited by the lack of suitable long-term data required for calibration. At any rate, predictions under climate change will require the incorporation of feedbacks among multiple components and beyond fire, including drought and soils. Consideration of multiple stabilizing and destabilizing feedback loops will be necessary to achieve realistic predictions, because climate change is leading to tree weakening and decline, which, as previously noted, may give rise to fuel limitations, or to novel processes such as the resprouting exhaustion syndrome. Pathogen and pest outbreaks, along with migratory flows (providing propagule adapted to the novel climatic conditions) will influence additionally the processes leading to state transitions.

\section{Avoiding post-fire deforestation through management}

We have only briefly discussed fire management options in this review although they can play a pivotal role in determining post-fire tree establishment. The literature on forest management of fire environments is rich, and a multitude of views exist (see full reviews in Baird 2006, Donato et al. 2006, Newton et al. 2006). Considering the information provided in this review, a few general guidelines may be drawn. Pre-fire management should aim at decreasing stand flammability and water scarcity as well as favoring seed production, which can be concomitantly achieved through reductions in tree density and basal area. Where the environmental characteristics and use of the land allow, additional resilience may be built by favoring/planting resprouter species (Granados et al. 2016). Nonetheless, care should be taken to more deeply understand the resprout exhaustion syndrome, as that could seriously limit the applicability of efforts toward increasing resilience by planting resprouting species. Additionally, any diversification should be done after assessing potential effects on stand flammability. Deeper examinations on the role of floristics vs. fuel load and structure will be needed to fully understand the implications of such species change on stand resilience (Zylstra et al. 2016).

After fire, there is a wide range of forestry operations that could be applied. At one end of the spectrum, salvage logging curtails beetles attracted to dead wood and removed wood could be used for bioenergy generation, but it could also compromise posterior regeneration through nutrient removal, soil compaction, and loss of fauna integral to ecosystem function. At the other end of the spectrum, leaving the stand untouched would protect 
soils from compaction but would complicate post-fire management by diminishing the capacity of navigating through the dead or fallen trees. An intermediate option is to fell the logs but leave them on ground, with or without partial biomass removal. Giving general recommendations is difficult as it ultimately depends upon fire intensity and severity, species, and site conditions (Castro et al. 2011). Regardless of the management technique chosen, soil preservation and erosion reduction, along with the preservation of the regeneration, should be at the forefront of efforts toward diminishing post-fire deforestation.

Considering the projected increases in mean annual temperature in the Mediterranean $\left(>3^{\circ} \mathrm{C}\right.$ in the area if the target of a global $2^{\circ} \mathrm{C}$ warming is achieved; Seneviratne et al. 2016), along with projected decreases in precipitation (Roderick et al. 2014) and subsequent increase in severe fire weather (Bedia et al. 2015), adequate management will be of utmost importance to ensure the persistence and sustainability of the ecosystem services currently provided by forests. We hope this review will contribute to achieving this goal.

\section{Conclusions}

Fire and drought play a major role in shaping spatial variation in the physiognomy of Mediterranean ecosystems across landscapes. Important knowledge gaps complicate predicting post-fire vegetation shifts. Understanding how plant traits affect both fire spread and postfire recovery represents an important challenge. While flammability at the leaf level is relatively well characterized, it is currently debated to what extent leaf traits scale to affect stand-level flammability and fire spread. In turn, fire spread and severity are major drivers of mortality in seeders, but predicting post-fire resprouting remains a major challenge. Future work should address to what extent adaptations to fire and drought are antagonistic in seeders and, in resprouters, to what extent pre-fire drought will impact resprout vigor.

It has been suggested that stand-replacing fires could enhance the sustainability of Mediterranean woodlands because post-fire seedlings will grow in competition-free environments. Consequently, high severity fire could serve to rejuvenate declining stands, although this may only apply under a limited set of environmental conditions (such as limited erosion rates and low fire recurrence, among others). Nonetheless, the demographic bottleneck for post-fire recovery would appear to be in the stages prior to seedling growth, namely, propagule availability and early establishment. Propagule availability is a function of the existence of aerial or edaphic seed banks (for on-site seed banks) and additionally of burned patch size (for off-site seed banks). Precipitation in the fall after the fire will be a major factor influencing the survival of early establishment. These initial rains play a disproportionately large effect on early establishment, and their effects last at least for a few years, until canopy closure and density-dependent processes start to develop.
Physiognomic and state shifts may occur when individuals succumb to fire and the regeneration of the population fails. Post-fire shifts in vegetation cover will depend upon the existing traits of the pre-fire community, drought (and other environmental factors), and the fire regime. We have provided a conceptual framework to aid in the determination of such state shifts. However, important knowledge gaps remain for understanding long-term vegetation dynamics and the stability of state transitions. For shifts in vegetation state to be stable, a feedback mechanism must be present in the system, but investigation of potential feedbacks is still ongoing. Additionally, climate change may reduce the climate space of different resprouter and seeder trees at different geographical locations and increasing drought intensity may also enhance insect and pathogen outbreaks, further hindering predictions on the stability of long-term changes. Increasing climate pressure and fire danger could lead Mediterranean forests to the brink of collapse and large-scale deforestation may be a reality for the turn of the 21 st century. Transitions of forests to non-forest states may be desirable or undesirable, depending on each case. We advocate for a comprehensive approach to tackle this issue.

\section{ACKNOWLEDGMents}

We acknowledge the support from the Erasmus Mundus Master Course Mediterranean Forestry and Natural Resources Management (MEDfOR), a Ramón y Cajal fellowship (RYC-201210970) and a grant from the Spanish Government (AGL201569151-R). The manuscript was substantially improved after feedback from the handling editor and four reviewers.

\section{Literature Cited}

Acácio, V., and M. Holmgren. 2014. Pathways for resilience in Mediterranean cork oak land use systems. Annals of Forest Science 71:5-13.

Acácio, V., M. Holmgren, F. Rego, F. Moreira, and G. M. J. Mohren. 2009. Are drought and wildfires turning Mediterranean cork oak forests into persistent shrublands? Agroforestry Systems 76:389-400.

Agee, J. K. 1998. Fire and pine ecosystems. Pages 193-218 in D. M. Richardson, editor. Ecology and biogeography of Pinus. Cambridge University Press, Cambridge, UK.

Alexander, M. E. 1988. Help with making crown fire assessments. In W. C. Fischer and S. F. Arno, editors. Protecting people and homes from wildfire in the Interior West: Proceedings of the Symposium and Workshop. US Department of Agriculture, Forest Service, Intermountain Research Station, Ogden, Utah, USA.

Alexander, M. E., and M. G. Cruz. 2013. Assessing the effect of foliar moisture on the spread rate of crown fires. International Journal of Wildland Fire 22:415-427.

Alfaro-Sánchez, R., J. Camarero, R. Sánchez-Salguero, G. Sangüesa-Barreda, and J. De Las Heras. 2016. Post-fire Aleppo pine growth, $\mathrm{C}$ and $\mathrm{N}$ isotope composition depend on site dryness. Trees 30:581-595.

Anderegg, W. R. L. 2015. Spatial and temporal variation in plant hydraulic traits and their relevance for climate change impacts on vegetation. New Phytologist 205:1008-1014.

Anderson, H. E. 1970. Forest fuel ignitibility. Fire Technology $6: 312-319$ 
Anderson, W. R., et al. 2015. A generic, empirical-based model for predicting rate of fire spread in shrublands. International Journal of Wildland Fire 24:443.

Ascoli, D., D. Castagneri, C. Valsecchi, M. Conedera, and G. Bovio. 2013. Post-fire restoration of beech stands in the Southern Alps by natural regeneration. Ecological Engineering 54:210-217.

Baar, J., T. R. Horton, A. Kretzer, and T. D. Bruns. 1999. Mycorrhizal colonization of Pinus muricata from resistant propagules after a stand-replacing wildfire. New Phytologist 2:409-418.

Baeza, M. J., J. Raventos, A. Escarre, and V. R. Vallejo. 2006. Fire risk and vegetation structural dynamics in Mediterranean shrubland. Plant Ecology 187:189-201.

Baeza, M. J., A. Valdecantos, J. A. Alloza, and R. V. Vallejo. 2007. Human disturbance and environmental factors as drivers of long-term post-fire regeneration patterns in Mediterranean forests. Journal of Vegetation Science 18:243-252.

Baeza, M. J., V. M. Santana, J. G. Pausas, and V. R. Vallejo. 2011. Successional trends in standing dead biomass in Mediterranean basin species. Journal of Vegetation Science 22: 467-474.

Baird, B. N. 2006. Comment on "Post-wildfire logging hinders regeneration and increases fire risk". Science 313:615.

Balfour, D. A., and J. J. Midgley. 2006. Fire induced stem death in an African acacia is not caused by canopy scorching. Austral Ecology 31:892-896.

Barbeta, A., and J. Peñuelas. 2016. Sequence of plant responses to droughts of different timescales: lessons from holm oak (Quercus ilex) forests. Plant Ecology and Diversity 9:1-18.

Barlow, J., B. O. Lagan, and C. A. Peres. 2003. Morphological correlates of fire-induced tree mortality in a central Amazonian forest. Journal of Tropical Ecology 19:291-299.

Barros, A. M., and J. M. Pereira. 2014. Wildfire selectivity for land cover type: Does size matter? PLoS ONE 9:e84760.

Batllori, E., M.-A. Parisien, M. A. Krawchuk, and M. A. Moritz. 2013. Climate change-induced shifts in fire for Mediterranean ecosystems. Global Ecology and Biogeography 22: $1118-1129$.

Batllori, E., D. D. Ackerly, and M. A. Moritz. 2015. A minimal model of fire-vegetation feedbacks and disturbance stochasticity generates alternative stable states in grassland-shrubland-woodland systems. Environmental Research Letters 10:034018.

Batllori, E., M. De Cáceres, L. Brotons, D. D. Ackerly, M. A. Moritz, and F. Lloret. 2017. Cumulative effects of fire and drought in Mediterranean ecosystems. Ecosphere 8:e01906.

Bazzaz, F. A. 1979. The physiological ecology of plant succession. Annual Review of Ecology and Systematics 10:351-371.

Bedia, J., S. Herrera, J. M. Gutiérrez, A. Benali, S. Brands, B. Mota, and J. M. Moreno. 2015. Global patterns in the sensitivity of burned area to fire-weather: Implications for climate change. Agricultural and Forest Meteorology 214-215: 369-379.

Blackman, C. J., S. Pfautsch, B. Choat, S. Delzon, S. M. Gleason, and R. A. Duursma. 2016. Toward an index of desiccation time to tree mortality under drought. Plant, Cell and Environment 39:2342-2345.

Boer, M. M., et al. 2016. Future changes in climatic water balance determine potential for transformational shifts in Australian fire regimes. Environmental Research Letters 11:065002.

Bond, W. J., and J. J. Midgley. 2003. The evolutionary ecology of sprouting in woody plants. International Journal of Plant Sciences 164:S103-S114

Bond, W. J., and J. J. Midgley. 2012. Fire and the angiosperm revolutions. International Journal of Plant Sciences 173:569 583.
Bond, W. J., and B. W. van Wilgen. 1996. Fire and plants. Chapman and Hall, London, UK.

Bonet, J. A., J. R. González-Olabarria, and J. M. Aragón. 2014. Mushroom production as an alternative for rural development in a forested mountainous area. Journal of Mountain Science 11:535-543.

Bova, A. S., and M. B. Dickinson. 2005. Linking surface-fire behavior, stem heating, and tissue necrosis. Canadian Journal of Forest Research 35:814-822.

Bowen, B. J., and J. S. Pate. 1993. The significance of root starch in postfire shoot recovery of the resprouter Stirlingia latifolia R. Br. (Proteaceae). Annals of Botany 72:7-16.

Bradshaw, S. D., K. W. Dixon, S. D. Hopper, H. Lambers, and S. R. Turner. 2011. Little evidence for fire-adapted plant traits in Mediterranean climate regions. Trends in Plant Science 16:69-76.

Brando, P. M., D. C. Nepstad, J. K. Balch, B. Bolker, M. C. Christman, M. Coe, and F. E. Putz. 2012. Fire-induced tree mortality in a neotropical forest: the roles of bark traits, tree size, wood density and fire behavior. Global Change Biology 18:630-641.

Brasier, C. M. 1996. Phytophtora cinnamomi and oak decline in southern Europe. Environmental constraints including climate change. Annals of Forest Science 53:347-358

Brodribb, T. J., and H. Cochard. 2009. Hydraulic failure defines the recovery and point of death in water-stressed conifers. Plant Physiology 149:575-584.

Büntgen, U., S. Egli, J. J. Camarero, E. M. Fischer, U. Stobbe, H. Kauserud, W. Tegel, L. Sproll, and N. C. Stenseth. 2012. Drought-induced decline in Mediterranean truffle harvest. Nature Climate Change 2:827-829.

Buscardo, E., H. Freitas, J. S. Pereira, and P. De Angelis. 2011. Common environmental factors explain both ectomycorrhizal species diversity and pine regeneration variability in a post-fire Mediterranean forest. Mycorrhiza 21:549-558.

Camarero, J. J., A. Gazol, J. C. Tardif, and F. Conciatori. 2015. Attributing forest responses to global-change drivers: limited evidence of a $\mathrm{CO}_{2}$-fertilization effect in Iberian pine growth. Journal of Biogeography 42:2220-2233.

Cardil, A., D. M. Molina, J. Oliveres, and M. Castellnou. 2016. Fire effects in Pinus uncinata Ram plantations. Forest Systems 25:eSC06.

Carnicer, J., M. Coll, M. Ninyerola, X. Pons, G. Sánchez, and J. Peñuelas. 2011. Widespread crown condition decline, food web disruption, and amplified tree mortality with increased climate change-type drought. Proceedings of the National Academy of Sciences USA 108:1474-1478.

Carrión, J. S., and S. Fernández. 2009. The survival of the 'natural potential vegetation' concept (or the power of tradition). Journal of Biogeography 36:2202-2203.

Castro, J., C. D. Allen, M. Molina-Morales, S. MarañónJiménez, Á. Sánchez-Miranda, and R. Zamora. 2011. Salvage logging versus the use of burnt wood as a nurse object to promote post-fire tree seedling establishment. Restoration Ecology 19:537-544.

Céspedes, B., I. Torres, B. Luna, B. Perez, and J. M. Moreno. 2012. Soil seed bank, fire season, and temporal patterns of germination in a seeder-dominated Mediterranean shrubland. Plant Ecology 213:383-393.

Chamorro, D., A. Parra, and J. M. Moreno. 2016. Reproductive output, seed anatomy and germination under water stress in the seeder Cistus ladanifer subjected to experimental drought. Environmental and Experimental Botany 123:59-67.

Chapin, F. S., E.-D. Schulze, and H. A. Mooney. 1990. The ecology and economics of storage in plants. Annual Review of Ecology and Systematics 21:423-447.

Chapin, F. S., J. T. Randerson, A. D. McGuire, J. A. Foley, and C. B. Field. 2008. Changing feedbacks in the 
climate-biosphere system. Frontiers in Ecology and the Environment 6:313-320.

Choat, B., et al. 2012. Global convergence in the vulnerability of forests to drought. Nature 491:752-755.

Choczynska, J., and E. A. Johnson. 2009. A soil heat and water transfer model to predict belowground grass rhizome bud death in a grass fire. Journal of Vegetation Science 20:277-287.

Clarke, P. J., M. J. Lawes, J. J. Midgley, B. B. Lamont, F. Ojeda, G. E. Burrows, N. J. Enright, and K. J. E. Knox. 2013. Resprouting as a key functional trait: how buds, protection and resources drive persistence after fire. New Phytologist 197:19-35.

Climent, J., R. Tapias, J. A. Pardos, and L. Gil. 2004. Fire adaptations in the Canary Islands pine (Pinus canariensis). Plant Ecology 171:185-196.

Cornwell, W. K., A. Elvira, L. van Kempen, R. S. van Logtestijn, A. Aptroot, and J. H. Cornelissen. 2015. Flammability across the gymnosperm phylogeny: the importance of litter particle size. New Phytologist 206:672-681.

Crawley, M. J. 1996. Plant ecology. Second edition. Blackwell Publishing, Cambridge, UK.

Cruz, A., and J. M. Moreno. 2001. Seasonal course of total non-structural carbohydrates in the lignotuberous Mediterranean-type shrub Erica australis. Oecologia 128:343-350.

Cruz, A., B. Pérez, and J. M. Moreno. 2003. Plant stored reserves do not drive resprouting of the lignotuberous shrub Erica australis. New Phytologist 157:251-261.

de Angelis, A., C. Ricotta, M. Conedera, and G. B. Pezzatti. 2015. Modelling the metrological forest fire niche in heterogeneous pyrologic conditions. PLoS ONE 10:e0116875.

De Luis, M., M. J. Baeza, J. Raventós, and J. C. GonzálezHidalgo. 2004. Fuel characteristics and fire behaviour in mature Mediterranean gorse shrublands. International Journal of Wildland Fire 13:79-87.

de Luis, M., M. Verdu, and J. Raventós. 2008. Early to rise makes a plant healthy, wealthy, and wise. Ecology 89:3061-3071.

DeAngelis, D., W. M. Post, and C. C. Travis. 1986. Positive feedback in natural systems. Springer-Verlag, Berlin, Germany.

Dennison, P. E., M. A. Moritz, and R. S. Taylor. 2008. Evaluating predictive models of critical live fuel moisture in the Santa Monica Mountains, California. International Journal of Wildland Fire 17:18-27.

Díaz-Delgado, R., F. Lloret, X. Pons, and J. Terradas. 2002. Satellite evidence of decreasing resilience in Mediterranean plant communities after recurrent wildfire. Ecology 83:2293-2303.

Dickinson, M. B. 2002. Heat transfer and vascular cambium necrosis in the boles of trees during surface fires. Pages 1-10 in D. Viegas, editor. Forest fire research \& wildland fire safety. Millpress, Rotterdam, The Netherlands.

Dickinson, M. B., and E. A. Johnson. 2001. Fire effects on trees. Pages 477-525 in E. A. Johnson and K. Miyanishi, editors. Forest fires: behavior and ecological effects. Academic Press, San Diego, California, USA.

Dickinson, M. B., and E. A. Johnson. 2004. Temperaturedependent rate models of vascular cambium cell mortality. Canadian Journal of Forest Research 34:546-559.

Donato, D. C., J. B. Fontaine, J. L. Campbell, W. D. Robinson, J. B. Kauffman, and B. E. Law. 2006. Post-wildfire logging hinders regeneration and increases fire risk. Science 311:352.

Duan, H., R. A. Duursma, G. Huang, R. A. Smith, B. Choat, A. P. O'Grady, and D. T. Tissue. 2014. Elevated $\left[\mathrm{CO}_{2}\right]$ does not ameliorate the negative effects of elevated temperature on drought-induced mortality in Eucalyptus radiata seedlings. Plant, Cell and Environment 37:1598-1613.

Duane, A., M. Piqué, M. Castellnou, and L. Brotons. 2015. Predictive modelling of fire occurrences from different fire spread patterns in Mediterranean landscapes. International Journal of Wildland Fire 24:407-418.
Ducrey, M., F. Duhoux, R. Huc, and E. Rigolot. 1996. The ecophysiological and growth responses of Aleppo pine (Pinus halepensis) to controlled heating applied to the base of the trunk. Canadian Journal of Forest Research 26:1366-1374.

Duursma, R. A., and B. E. Medlyn. 2012. MAESPA: a model to study interactions between water limitation, environmental drivers and vegetation function at tree and stand levels, with an example application to $\left[\mathrm{CO}_{2}\right] \times$ drought interactions. Geoscientific Model Development 5:919-940.

Erdmann, T. K., P. K. R. Nair, and B. T. Kang. 1993. Effects of cutting frequency and cutting height on reserve carbohydrates in Gliricidia sepium (Jacq.) Walp. Forest Ecology and Management 57:45-60.

Escudero, A., M. V. Sanz, J. M. Pita, and F. Pérez-García. 1999. Probability of germination after heat treatment of native Spanish pines. Annals of Forest Science 56:511-520.

Fensham, R. J., R. J. Fairfax, and D. P. Ward. 2009. Droughtinduced tree death in savanna. Global Change Biology 15:380-387.

Fernandes, P. M., and M. G. Cruz. 2012. Plant flammability experiments offer limited insight into vegetation-fire dynamics interactions. New Phytologist 194:606-609.

Fernandes, P., and F. Rego. 1998. A new method to estimate fuel surface area-to-volume ratio using water immersion. International Journal of Wildland Fire 8:121-128.

Fernandes, P. M., and E. Rigolot. 2007. The fire ecology and management of maritime pine (Pinus pinaster Ait.). Forest Ecology and Management 241:1-13.

Fernandes, P. M., J. A. Vega, E. Jiménez, and E. Rigolot. 2008. Fire resistance of European pines. Forest Ecology and Management 256:246-255.

Fernandes, P. M., T. Monteiro-Henriques, N. Guiomar, C. Loureiro, and A. M. G. Barros. 2016. Bottom-up variables govern large-fire size in Portugal. Ecosystems 19:1362-1375.

Fernández-de-Uña, L., N. G. McDowell, I. Cañellas, G. GeaIzquierdo, and C. Canham. 2016. Disentangling the effect of competition, $\mathrm{CO}_{2}$ and climate on intrinsic water-use efficiency and tree growth. Journal of Ecology 104:678-690.

Flematti, G. R., E. L. Ghisalberti, K. W. Dixon, and R. D. Trengove. 2004. A compound from smoke that promotes seed germination. Science 305:977.

Fulé, P. Z., M. Ribas, E. Gutiérrez, R. Vallejo, and M. W. Kaye. 2008. Forest structure and fire history in an old Pinus nigra forest, eastern Spain. Forest Ecology and Management 255: $1234-1242$

Ganteaume, A., M. Jappiot, T. Curt, C. Lampin, and L. Borgniet. 2014. Flammability of litter sampled according to two different methods: comparison of results in laboratory experiments. International Journal of Wildland Fire 23:1061-1075.

García, Y., M. C. Castellanos, and J. G. Pausas. 2016. Fires can benefit plants by disrupting antagonistic interactions. Oecologia 182:1165-1173.

Giglio, L., J. T. Randerson, and G. R. van der Werf. 2013. Analysis of daily, monthly, and annual burned area using the fourth-generation global fire emissions database (GFED4). Journal of Geophysical Research: Biogeosciences 118:317328 .

Gil, L., R. López, Á. García-Mateos, and I. González-Doncel. 2009. Seed provenance and fire-related reproductive traits of Pinus pinaster in central Spain. International Journal of Wildland Fire 18:1003-1009.

Gill, A. M. 1973. Effects of fire on Australia's natural vegetation: annual report. CSIRO, Division of Plant Industry, Canberra, Australian Capital Territory, Australia.

Gill, A., and D. Ashton. 1968. The role of bark type in relative tolerance to fire of three central Victorian Eucalypts. Australian Journal of Botany 16:491. 
Gil-Pelegrín, E., J. J. Peguero-Pina, J. J. Camarero, A. Fernández-Cancio, and R. Navarro-Cerrillo. 2008. Drought and forest decline in the Iberian Peninsula: A simple explanation for a complex phenomenon? Pages 27-68 in J. M. Sánchez, editor. Droughts: causes, effects and predictions. Nova Science Publishers, New York, New York, USA.

Gil-Romera, G., et al. 2014. Biomass-modulated fire dynamics during the last glacial-interglacial transition at the Central Pyrenees (Spain). Palaeogeography, Palaeoclimatology, Palaeoecology 402:113-124.

Gómez, J. M. 2003. Spatial patterns in long-distance dispersal of Quercus ilex acorns by jays in a heterogeneous landscape. Ecography 26:573-584.

Gómez-Aparicio, L., J. Domínguez-Begines, P. Kardol, J. M. Ávila, B. Ibáñez, and L. V. García. 2017. Plant-soil feedbacks in declining forests: implications for species coexistence. Ecology 98:1908-1921.

González, J. R., A. Trasobares, M. Palahí, and T. Pukkala. 2007. Predicting stand damage and tree survival in burned forests in Catalonia (North-East Spain). Annals of Forest Science 64:733-742.

Granados, M. E., A. Vilagrosa, E. Chirino, and V. R. Vallejo. 2016. Reforestation with resprouter species to increase diversity and resilience in Mediterranean pine forests. Forest Ecology and Management 362:231-240.

Granda, E., D. R. Rossatto, J. J. Camarero, J. Voltas, and F. Valladares. 2014. Growth and carbon isotopes of Mediterranean trees reveal contrasting responses to increased carbon dioxide and drought. Oecologia 174:307-317.

Grime, J. P. 1977. Evidence for the existence of three primary strategies in plants and its relevance to ecological and evolutionary theory. American Naturalist 111:1169-1194.

Grootemaat, S., I. J. Wright, P. M. van Bodegom, J. H. C. Cornelissen, W. K. Cornwell, and J. Schweitzer. 2015. Burn or rot: leaf traits explain why flammability and decomposability are decoupled across species. Functional Ecology 29:1486-1497.

Grossiord, C., et al. 2014. Tree diversity does not always improve resistance of forest ecosystems to drought. Proceedings of the National Academy of Sciences USA 111:1481214815.

Gutsell, S. L., and E. A. Johnson. 1996. How fire scars are formed: coupling a disturbance process to its ecological effects. Canadian Journal of Forest Research 26:166-174.

Habrouk, A., J. Retana, and J. Espelta. 1999. Role of heat tolerance and cone protection of seeds in the response of three pine species to wildfires. Plant Ecology 145:91-99.

Hanes, T. L. 1971. Succession after fire in the chaparral of Southern California. Ecological Monographs 41:27-52.

Hare, R. C. 1965. Bark surface and cambium temperatures in simulated forest fires. Journal of Forestry 63:437-440.

Hartford, R., and W. Frandsen. 1992. When it's hot, it's hot. . or maybe it's not! (Surface flaming may not portend extensive soil heating). International Journal of Wildland Fire 2:139.

Helgerson, O. T. 1990. Heat damage in tree seedlings and its prevention. New Forests 3:333-358.

Hengst, G. E., and J. O. Dawson. 1994. Bark properties and fire resistance of selected tree species from the central hardwood region of North America. Canadian Journal of Forest Research 24:688-696.

Hijmans, R. J., S. E. Cameron, J. L. Parra, P. G. Jones, and A. Jarvis. 2005. Very high resolution interpolated climate surfaces for global land areas. International Journal of Climatology 25:1965-1978.

Hinojosa, M. B., A. Parra, V. A. Laudicina, and J. M. Moreno. 2016. Post-fire soil functionality and microbial community structure in a Mediterranean shrubland subjected to experimental drought. Science of the Total Environment 573:1178-1189.
Hoffmann, W. A., E. L. Geiger, S. G. Gotsch, D. R. Rossatto, L. C. R. Silva, O. L. Lau, M. Haridasan, and A. C. Franco. 2012. Ecological thresholds at the savanna-forest boundary: how plant traits, resources and fire govern the distribution of tropical biomes. Ecology Letters 15:759-768.

Holz, A., T. Kitzberger, J. Paritsis, and T. T. Veblen. 2012. Ecological and climatic controls of modern wildfire activity patterns across southwestern South America. Ecosphere 3:103.

IPCC. 2014. Summary for Policymakers. In: Climate Change 2014: Impacts, adaptation, and vulnerability. Part A: global and sectoral aspects. Contribution of Working Group II to the Fifth Assessment Report of the Intergovernmental Panel on Climate Change, Cambridge University Press, Cambridge, UK and New York, New York, USA.

Jones, J. L., B. W. Webb, B. W. Butler, M. B. Dickinson, D. Jimenez, J. Reardon, and A. S. Bova. 2006. Prediction and measurement of thermally induced cambial tissue necrosis in tree stems. International Journal of Wildland Fire 15:3.

Jurdao, S., M. Yebra, J. P. Guerschman, and E. Chuvieco. 2013. Regional estimation of woodland moisture content by inverting radiative transfer models. Remote Sensing of Environment 132:59-70.

Juvany, M., M. Müller, and S. Munné-Bosch. 2015. Bud vigor, budburst lipid peroxidation, and hormonal changes during bud development in healthy and moribund beech (Fagus sylvatica L.) trees. Trees 29:1781-1790.

Karhu, K., et al. 2015. Fire increases the risk of higher soil $\mathrm{N}_{2} \mathrm{O}$ emissions from Mediterranean Macchia ecosystems. Soil Biology and Biochemistry 82:44-51.

Kavanagh, K. L., M. B. Dickinson, and A. S. Bova. 2010. A way forward for fire-caused tree mortality prediction: Modeling a physiological consequence of fire. Fire Ecology 6:80-94.

Keane, R. E. 2015. Wildland fuel fundamentals and applications. Springer, New York.

Keane, R. E., E. D. Reinhardt, J. Scott, K. Gray, and J. Reardon. 2005. Estimating forest canopy bulk density using six indirect methods. Canadian Journal of Forest Research 35: 724-739.

Keeley, J. E. 2009. Fire intensity, fire severity and burn severity: a brief review and suggested usage. International Journal of Wildland Fire 18:116-126.

Keeley, J. E. 2012. Ecology and evolution of pine life histories. Annals of Forest Science 69:445-453.

Keeley, J. E., and C. J. Fotheringham. 2000. Role of fire in regeneration from seed. Seeds: The Ecology of Regeneration in Plant Communities 2:311-330.

Keeley, J. E., C. J. Fotheringham, and M. Morais. 1999. Reexamining fire suppression impacts on brushland fire regimes. Science 284:1829-1832.

Keeley, J. E., G. H. Aplet, N. L. Christensen, S. G. Conard, E. A. Johnson, P. N. Omi, D. L. Peterson, and T. W. Swetnam. 2009. Ecological foundations for fire management in North America forest and shrubland ecosystems. General Technical Report, PNW-GTR-779. USDA Forest Service, Pacific Northwest Research Station, Cambridge.

Keeley, J. E., J. G. Pausas, P. W. Rundel, W. J. Bond, and R. A. Bradstock. 2011. Fire as an evolutionary pressure shaping plant traits. Trends in Plant Science 16:406-411.

Keeley, J. E., W. J. Bond, R. A. Bradstock, J. G. Pausas, and P. W. Rundel. 2012. Fire in Mediterranean ecosystems-ecology, evolution and management. Cambridge University Press, Cambridge, UK.

Knorr, W., A. Arneth, and L. Jiang. 2016. Demographic controls of future global fire risk. Nature Climate Change 6:781-785.

Kolstrom, T., and S. Kellomaki. 1993. Tree survival in wildfires. Silva Fennica 27:277-281. 
Korner, C. 2003. Carbon limitation in trees. Journal of Ecology 91:4-17.

Kramer, P. J., and T. T. Kozlowski. 1960. Physiology of trees. McGraw-Hill Book Company, New York, New York, USA.

Lamont, B. B., E. T. F. Witkowski, and N. J. Enright. 1993 Post-fire litter microsites: Safe for seeds, unsafe for seedlings. Ecology 74:501-512.

Lankau, R. A., K. Zhu, and A. Ordóñez. 2015. Mycorrhizal strategies of tree species correlate with trailing range edge responses to current and past climate change. Ecology 96:1451-1458.

Lanner, R. M. 1998. Seed dispersal in Pinus. Pages 281-295 in D. M. Richardson, editor. Ecology and biogeography of Pinus. Cambridge University Press, Cambridge, UK.

Lawes, M. J., A. Richards, J. Dathe, and J. J. Midgley. 2011. Bark thickness determines fire resistance of selected tree species from fire-prone tropical savanna in north Australia. Plant Ecology 212:2057-2069.

Linder, P., P. Jonsson, and M. Niklasson. 1998. Tree mortality after prescribed burning in an old-growth Scots pine forest in northern Sweden. Silva Fennica 32:339-349.

Lloret, F. 1998. Fire, canopy cover and seedling dynamics in Mediterranean shrubland of Northeastern Spain. Journal of Vegetation Science 9:417-430.

Loepfe, L., J. Martinez-Vilalta, J. Oliveres, J. Piñol, and F. Lloret. 2010. Feedbacks between fuel reduction and landscape homogenisation determine fire regimes in three Mediterranean areas. Forest Ecology and Management 259:2366-2374.

Madrigal, J., C. Hernando, E. Martínez, M. Guijarro, and C. Díez. 2005. Regeneración post-incendio de Pinus pinaster Ait. en la Sierra de Guadarrama (Sistema Central, España): modelos descriptivos de los factores influyentes en la densidad inicial y la supervivencia. Investigación Agraria. Sistemas y Recursos Forestales 14:36-51

Madrigal, J., E. Marino, M. Guijarro, C. Hernando, and C. Díez. 2011. Evaluation of the flammability of gorse (Ulex europaeus L.) managed by prescribed burning. Annals of Forest Science 69:387-397.

MAGRAMA. 2012. Los incendios forestales en España. Decenio 2001-2010. MAGRAMA, Madrid, Spain.

Martín-Alcón, S., and L. Coll. 2016. Unraveling the relative importance of factors driving post-fire regeneration trajectories in non-serotinous Pinus nigra forests. Forest Ecology and Management 361:13-22.

Martín-Alcón, S., L. Coll, and A. Ameztegui. 2015. Diversifying sub-Mediterranean pinewoods with oak species in a context of assisted migration: responses to local climate and light environment. Applied Vegetation Science 19:254-266.

Martínez de Aragón, J., C. Fischer, J. A. Bonet, A. Olivera, D. Oliach, and C. Colinas. 2012. Economically profitable post fire restoration with black truffle (Tuber melanosporum) producing plantations. New Forests 43:615-630.

Matthews, J. D. 1991. Silvicultural systems. Oxford University Press, Oxford, UK.

Mayor, A. G., A. Valdecantos, V. R. Vallejo, J. J. Keizer, J. Bloem, J. Baeza, O. Gonzalez-Pelayo, A. I. Machado, and P. C. de Ruiter. 2016. Fire-induced pine woodland to shrubland transitions in Southern Europe may promote shifts in soil fertility. Science of the Total Environment 573:12321241.

McDowell, N. G. 2011. Mechanisms linking drought, hydraulics, carbon metabolism, and vegetation mortality. Plant Physiology 155:1051-1059.

McDowell, N., et al. 2008. Mechanisms of plant survival and mortality during drought: Why do some plants survive while others succumb to drought? New Phytologist 178:719-739.
McKenzie, D., and J. S. Littell. 2016. Climate change and the eco-hydrology of fire: Will area burned increase in a warming western U.S.? Ecological Applications 27:26-36.

Mediavilla, S., A. Garcia-Ciudad, B. Garcia-Criado, and A. Escudero. 2008. Testing the correlations between leaf life span and leaf structural reinforcement in 13 species of European Mediterranean woody plants. Functional Ecology 22: 787-793.

Mencuccini, M., F. Minunno, Y. Salmon, J. Martinez-Vilalta, and T. Holtta. 2015. Coordination of physiological traits involved in drought-induced mortality of woody plants. New Phytologist 208:396-409.

Michaletz, S. T., and E. A. Johnson. 2007. How forest fires kill trees: A review of the fundamental biophysical processes. Scandinavian Journal of Forest Research 22:500-515.

Michaletz, S. T., and E. A. Johnson. 2008. A biophysical process model of tree mortality in surface fires. Canadian Journal of Forest Research 38:2013-2029.

Michaletz, S. T., E. A. Johnson, and M. T. Tyree. 2012. Moving beyond the cambium necrosis hypothesis of post-fire tree mortality: cavitation and deformation of xylem in forest fires. New Phytologist 194:254-263.

Midgley, J. J., M. J. Lawes, and S. Chamaillé-Jammes. 2010. Savanna woody plant dynamics: the role of fire and herbivory, separately and synergistically. Australian Journal of Botany 58:1-11.

Midgley, J. J., L. M. Kruger, and R. Skelton. 2011. How do fires kill plants? The hydraulic death hypothesis and Cape Proteaceae "fire-resisters". South African Journal of Botany 77:381386.

Morales-Molino, C., W. Tinner, M. García-Antón, and D. Colombaroli. 2016. The historical demise of Pinus nigra forests in the Northern Iberian Plateau (south-western Europe). Journal of Ecology. https://doi.org/10.1111/1365-2745.12702.

Moreira, F., M. Arianoutsou, P. Corona, and J. D. L. Heras. 2012. Post-fire management and restoration of southern European forests. Springer, Berlin.

Moreno, J. M., and W. C. Oechel. 1991. Fire intensity and herbivory effects on postfire resprouting of Adenostoma fasciculatum in southern California chaparral. Oecologia 85: 429-433.

Moreno, J. M., E. Zuazua, B. Pérez, B. Luna, A. Velasco, and V. Resco De Dios. 2011. Rainfall patterns after fire differentially affect the recruitment of three Mediterranean shrubs. Biogeosciences 8:3721-3732.

Moreno, J. M., V. R. Vallejo, and E. Chuvieco. 2013. Current fire regimes, impacts and the likely changes VI: Euro Mediterranean. Pages 115-132 in J. G. Goldammer, editor. Vegetation fires and global change. Kessel Publishing House, RemagenOberwinter, Germany.

Munné-Bosch, S. 2015. Senescence: Is it universal or not? Trends in Plant Science 20:713-720.

Newton, M., S. Fitzgerald, R. R. Rose, P. W. Adams, S. D. Tesch, J. Sessions, T. Atzet, R. F. Powers, and C. Skinner. 2006. Comment on "Post-wildfire logging hinders regeneration and increases fire risk". Science 313:615.

Noble, I. R., and R. O. Slatyer. 1980. The use of vital attributes to predict successional changes in plant communities subject to recurrent disturbances. Vegetatio 43:5-21.

Nolan, R. H., M. M. Boer, V. Resco de Dios, G. Caccamo, and R. A. Bradstock. 2016. Large scale, dynamic transformations in fuel moisture drive wildfire activity across south-eastern Australia. Geophysical Research Letters 43:4229-4238.

Nunes, M. C. S., M. J. Vasconcelos, J. M. C. Pereira, N. Dasgupta, R. J. Alldredge, and F. C. Rego. 2005. Land cover type and fire in Portugal: Do fires burn land cover selectively? Landscape Ecology 20:661-673. 
Odion, D. C., M. A. Moritz, and D. A. Dellasala. 2010. Alternative community states maintained by fire in the Klamath Mountains, USA. Journal of Ecology 98:96-105.

Oliva, J., J. Stenlid, and J. Martinez-Vilalta. 2014. The effect of fungal pathogens on the water and carbon economy of trees: implications for drought-induced mortality. New Phytologist 203:1028-1035.

Ordoñez, J., R. Molowny-Horas, and J. Retana. 2006. A model of the recruitment of Pinus nigra from unburned edges after large wildfires. Ecological Modelling 197:405-417.

Ordóñez, J. L., J. Retana, and J. M. Espelta. 2005. Effects of tree size, crown damage, and tree location on post-fire survival and cone production of Pinus nigra trees. Forest Ecology and Management 206:109-117.

Parra, A., and J. M. Moreno. 2017. Post-fire environments are favourable for plant functioning of seeder and resprouter Mediterranean shrubs, even under drought. New Phytologist 214:1118-1131.

Pate, J. S., R. H. Froend, B. J. Bowen, A. Hansen, and J. Kuo. 1990. Seedling growth and storage characteristics of seeder and resprouter species of Mediterranean-type ecosystems of S.W. Australia. Annals of Botany 65:585-601.

Paula, S., and F. Ojeda. 2009. Belowground starch consumption after recurrent severe disturbance in three resprouter species of the genus Erica. Botany 87:253-259.

Pausas, J. G. 2015a. Bark thickness and fire regime. Functional Ecology 29:315-327.

Pausas, J. G. 2015b. Evolutionary fire ecology: lessons learned from pines. Trends in Ecology and Evolution 20:318-324.

Pausas, J., and R. A. Bradstock. 2007. Plant persistence fire traits along a productivity and disturbance gradient in Mediterranean shrublands of southeastern Australia. Global Ecology and Biogeography 16:330-340.

Pausas, J. G., and S. Fernández-Muñoz. 2011. Fire regime changes in the Western Mediterranean Basin: from fuel-limited to drought-driven fire regime. Climatic Change 110:215226.

Pausas, J. G., and B. Moreira. 2012. Flammability as a biological concept. New Phytologist 194:610-613.

Pausas, J. G., and E. Ribeiro. 2013. The global fire-productivity relationship. Global Ecology and Biogeography 22:728-736.

Pausas, J. G., N. Ouadah, A. Ferran, T. Gimeno, and R. Vallejo. 2003. Fire severity and seedling establishment in Pinus halepensis woodlands, eastern Iberian Peninsula. Plant Ecology 169:205-213.

Pausas, J. G., C. Blade, A. Valdecantos, J. P. Seva, D. Fuentes, J. A. Alloza, A. Vilagrosa, S. Bautista, J. Cortina, and R. Vallejo. 2004. Pines and oaks in the restoration of Mediterranean landscapes of Spain: New perspectives for an old practice-a review. Plant Ecology 171:209-220.

Pausas, J., J. Llovet, A. Rodrigo, and R. Vallejo. 2008. Are wildfires a disaster in the Mediterranean basin? A review. International Journal of Wildland Fire 17:713-723.

Pausas, J. G., R. B. Pratt, J. E. Keeley, A. L. Jacobsen, A. R. Ramirez, A. Vilagrosa, S. Paula, I. N. Kaneakua-Pia, and S. D. Davis. 2015. Towards understanding resprouting at the global scale. New Phytologist 209:945-954.

Peguero, G., and J. M. Espelta. 2011. Disturbance intensity and seasonality affect the resprouting ability of the neotropical dry-forest tree Acacia pennatula: Do resources stored belowground matter? Journal of Tropical Ecology 27:539-546.

Peguero-Pina, J. J., D. Sancho-Knapik, P. Martín, M. Á. Saz, G. Gea-Izquierdo, I. Cañellas, and E. Gil-Pelegrín. 2015. Evidence of vulnerability segmentation in a deciduous Mediterranean oak (Quercus subpyrenaica E. H. del Villar). Trees 29:1917-1927.
Pellizzaro, G., P. Duce, A. Ventura, and P. Zara. 2007. Seasonal variations of live moisture content and ignitability in shrubs of the Mediterranean Basin. International Journal of Wildland Fire 16:633-641.

Peñuelas, J., and R. Matamala. 1990. Changes in N and S leaf content, stomatal density and specific leaf area of 14 plant species during the last three centuries of $\mathrm{CO}_{2}$ increase. Journal of Experimental Botany 41:1119-1124.

Peñuelas, J., et al. 2017. Assessment of the impacts of climate change on Mediterranean terrestrial ecosystems based on data from field experiments and long-term monitored field gradients in Catalonia. Environmental and Experimental Botany. https://doi.org/10.1016/j.envexpbot.2017.05.012.

Peterson, D. L. 1985. Crown scorch volume and scorch height: estimates of postfire tree condition. Canadian Journal of Forest Research 15:596-598.

Pinard, M. A., and J. Huffman. 1997. Fire resistance and bark properties of trees in a seasonally dry forest in eastern Bolivia. Journal of Tropical Ecology 13:727-740.

Piñol, J., K. Beven, and D. X. Viegas. 2005. Modelling the effect of fire-exclusion and prescribed fire on wildfire size in Mediterranean ecosystems. Ecological Modelling 183:397409.

Pratt, R. B., A. L. Jacobsen, A. R. Ramirez, A. M. Helms, C. A. Traugh, M. F. Tobin, M. S. Heffner, and S. D. Davis. 2014. Mortality of resprouting chaparral shrubs after a fire and during a record drought: physiological mechanisms and demographic consequences. Global Change Biology 20:893907.

Pulsford, S. A., D. B. Lindenmayer, and D. A. Driscoll. 2016. A succession of theories: purging redundancy from disturbance theory. Biological Reviews 91:148-167.

Quero, J. L., L. Gómez-Aparicio, R. Zamora, and F. T. Maestre. 2008. Shifts in the regeneration niche of an endangered tree (Acer opalus ssp. granatense) during ontogeny: Using an ecological concept for application. Basic and Applied Ecology 9:635-644.

Quintana, J. R., A. Cruz, F. Fernández-González, and J. M. Moreno. 2004. Time of germination and establishment success after fire of three obligate seeders in a Mediterranean shrubland of central Spain. Journal of Biogeography 31:241249 .

Ramírez, D. A., A. Parra, V. Resco de Dios, and J. M. Moreno. 2012. Differences in morpho-physiological leaf traits reflect the response of growth to drought in a seeder but not in a resprouter Mediterranean species. Functional Plant Biology 39:332-341.

Resco de Dios, V. 2016. When fire acts like an irrigation: competition release after burning enhances growth. Trees 30:579580

Resco de Dios, V., C. Fischer, and C. Colinas. 2007. Climate change effects on Mediterranean forests and preventive measures. New Forests 33:29-40.

Resco de Dios, V., J. F. Weltzin, W. Sun, T. E. Huxman, and D. G. Williams. 2014. Transitions from grassland to savanna under drought through passive facilitation by grasses. Journal of Vegetation Science 25:937-946.

Resco de Dios, V., T. E. Mereed, J. P. Ferrio, D. T. Tissue, and J. Voltas. 2016. Intraspecific variation in juvenile tree growth under elevated $\mathrm{CO}_{2}$ alone and with $\mathrm{O}_{3}$ : a meta-analysis. Tree Physiology 36:682-693.

Resco, V., B. E. Ewers, W. Sun, T. E. Huxman, J. F. Weltzin, and D. G. Williams. 2009. Drought-induced hydraulic limitations constrain leaf gas exchange recovery after precipitation pulses in the $\mathrm{C}_{3}$ woody legume, Prosopis velutina. New Phytologist 181:672-682. 
Retana, J., J. M. Espelta, A. Habrouk, J. L. Ordóñez, and F. de Solà-Morales. 2002. Regeneration patterns of three Mediterranean pines and forest changes after a large wildfire in northeastern Spain. Écoscience 9:89-97.

Richard, F., M. A. Selosse, and M. Gardes. 2009. Facilitated establishment of Quercus ilex in shrub-dominated communities within a Mediterranean ecosystem: Do mycorrhizal partners matter? FEMS Microbiology Ecology 68:14-24.

Richards, J. H., and M. M. Caldwell. 1985. Soluble carbohydrates, concurrent photosynthesis and efficiency in regrowth following defoliation: a field study with Agropyron species. Journal of Applied Ecology 22:907.

Rivas-Martínez, S., et al. 2005. Mapa de series, geoseries y geopermaseries de vegetación de España. Phytosociological Research Center, Madrid, Spain.

Roderick, M. L., F. Sun, W. H. Lim, and G. D. Farquhar. 2014. A general framework for understanding the response of the water cycle to global warming over land and ocean. Hydrology and Earth System Sciences 18:1575-1589.

Rodrigo, A., V. Quintana, and J. Retana. 2007. Fire reduces Pinus pinea distribution in the north-eastern Iberian Peninsula. Écoscience 14:23-30.

Rosell, J. A. 2016. Bark thickness across the angiosperms: more than just fire. New Phytologist 211:90-102.

Rosenberg, B., G. Kemeny, R. C. Switzer, and T. C. Hamilton. 1971. Quantitative evidence for protein denaturation as the cause of thermal death. Nature 232:471-473.

Rotenberg, E., and D. Yakir. 2010. Contribution of semi-arid forests to the climate system. Science 327:451-454.

Rothermel, R. C. 1972. A mathematical model for predicting fire spread in wildland fuels. Research Paper INT-115. USDA Forest Service, Intermountain Forest and Range Experiment Station, Ogden, Utah, USA.

Rowland, L., et al. 2015. Death from drought in tropical forests is triggered by hydraulics not carbon starvation. Nature 528:119-122.

Ruiz-Labourdette, D., D. Nogués-Bravo, H. S. Ollero, M. F. Schmitz, and F. D. Pineda. 2012. Forest composition in Mediterranean mountains is projected to shift along the entire elevational gradient under climate change. Journal of Biogeography 39:162-176.

Rundel, P. W. 1973. The relationship between basal fire scars and crown damage in Giant Sequoia. Ecology 54:210-213.

Rundel, P. W. 2007. Mediterranean-climate ecosystems. Pages 1-15 in S. A. Levin, editor. Encyclopedia of biodiversity. Elsevier, New York.

Ryan, K. C., and E. D. Reinhardt. 1988. Predicting postfire mortality of seven western conifers. Canadian Journal of Forest Research 18:1291-1297.

Sagra, J., D. Moya, P. Plaza-Álvarez, M. Lucas-Borja, R. Alfaro-Sánchez, J. De Las Heras, and P. Ferrandis. 2017. Predation on early recruitment in Mediterranean forests after prescribed fires. Forests 8:243.

San-Miguel-Ayanz, J. S., M. Rodrigues, S. Santos de Oliveira, C. Kemper Pacheco, F. Moreira, B. Duguy, and A. Camia. 2012. Land cover change and fire regime in the European Mediterranean region. Pages 21-43 in F. Moreira, M. Arianoutsou, P. Corona, and J. De las Heras, editors. Post-fire management and restoration of southern European forests. Springer-Verlag, New York, New York, USA.

Santana, V. M., M. J. Baeza, R. H. Marrs, and V. R. Vallejo. 2010. Old-field secondary succession in SE Spain: Can fire divert it? Plant Ecology 211:337-349.

Santana, V. M., M. J. Baeza, and F. T. Maestre. 2012. Seedling establishment along post-fire succession in Mediterranean shrublands dominated by obligate seeders. Acta Oecologica 39:51-60.
Santos-del-Blanco, L., J. Climent, and S. Bonser. 2014. Costs of female reproduction in a conifer tree: a whole-tree level assessment. Journal of Ecology 102:1310-1317.

Schoonenberg, T., M. Pinard, and S. Woodward. 2003. Responses to mechanical wounding and fire in tree species characteristic of seasonally dry tropical forest of Bolivia. Canadian Journal of Forest Research 33:330-338.

Schulze, E. D., E. Beck, and K. Müller-Hohenstein. 2005. Plant ecology. Springer, Berlin.

Schwilk, D. W. 2003. Flammability is a niche construction trait: Canopy architecture affects fire intensity. American Naturalist 162:725-733.

Scott, A. C., D. M. J. S. Bowman, W. J. Bond, S. J. Pyne, and M. E. Alexander. 2014. Fire on earth: an introduction. WileyBlackwell, Chichester, UK.

Seneviratne, S. I., M. G. Donat, A. J. Pitman, R. Knutti, and R. L. Wilby. 2016. Allowable $\mathrm{CO}_{2}$ emissions based on regional and impact-related climate targets. Nature 529:477-483.

Shakesby, R. A. 2011. Post-wildfire soil erosion in the Mediterranean: Review and future research directions. Earth-Science Reviews 105:71-100.

Shestakova, T. A., E. Gutiérrez, A. V. Kirdyanov, J. J. Camarero, M. Génova, A. A. Knorre, J. C. Linares, V. Resco de Dios, R. Sánchez-Salguero, and J. Voltas. 2016. Forests synchronize their growth in contrasting Eurasian regions in response to climate warming. Proceedings of the National Academy of Sciences USA 113:662-667.

Sidoroff, K., T. Kuuluvainen, H. Tanskanen, and I. VanhaMajamaa. 2007. Tree mortality after low-intensity prescribed fires in managed Pinus sylvestris stands in southern Finland. Scandinavian Journal of Forest Research 22:2-12.

Sieg, C. H., J. D. McMillin, J. F. Fowler, K. K. Allen, J. F. Negron, L. L. Wadleigh, J. A. Anhold, and K. E. Gibson. 2006. Best predictors for postfire mortality of ponderosa pine trees in the intermountain west. Forest Science 52:718-728.

Simard, S., K. Martin, A. Vyse, and B. Larson. 2013. Meta-networks of fungi, fauna and flora as agents of complex adaptive systems. Pages 133-164 in C. Messier, K. J. Puettmann, and K. D. Coates, editors. Managing forests as complex adaptive systems: building resilience to the challenge of global change. Routledge, New York, New York, USA.

Skelton, R. P., T. J. Brodribb, S. A. M. McAdam, and P. J. Mitchell. 2017. Gas exchange recovery following natural drought is rapid unless limited by loss of leaf hydraulic conductance: evidence from an evergreen woodland. New Phytologist 215:1399-1412.

Slimani, S., R. Touchan, A. Derridj, D. Kherchouche, and E. Gutiérrez. 2014. Fire history of Atlas cedar (Cedrus atlantica Manetti) in Mount Chélia, northern Algeria. Journal of Arid Environments 104:116-123.

Smith, S. E., and D. J. Read. 2008. Mycorrhizal symbiosis. Third edition. Academic Press, New York, New York, USA.

Soler Martin, M., J. A. Bonet, J. Martínez De Aragón, J. Voltas, L. Coll, and V. Resco De Dios. 2017. Crown bulk density and fuel moisture dynamics in Pinus pinaster stands are neither modified by thinning nor captured by the forest fire weather index. Annals of Forest Science 74:51.

Sperry, J. S., F. R. Adler, G. S. Campbell, and J. P. Compstock. 1998. Limitation of plant water use by rhizosphere and xylem conductance: results from a model. Plant Cell and Environment 21:347-359.

Stephens, S. L., and M. A. Finney. 2002. Prescribed fire mortality of Sierra Nevada mixed conifer tree species: effects of crown damage and forest floor combustion. Forest Ecology and Management 162:261-271.

Tapias, R., J. Climent, J. A. Pardos, and L. Gil. 2004. Life histories of Mediterranean pines. Plant Ecology 171:53-68. 
Taudière, A., F. Richard, and C. Carcaillet. 2017. Review on fire effects on ectomycorrhizal symbiosis, an unachieved work for a scalding topic. Forest Ecology and Management 391:446457.

Thanos, C. A., and E. N. Daskalakou. 2000. Reproduction in Pinus halepensis and P. brutia. Pages 79-90 in G. Néeman and L. Trabaud, editors. Ecology, biogeography and management of Pinus halepensis and P. brutia forest ecosystems in the Mediterranean Basin. Backhuys Publishers, Leiden, The Netherlands.

Tomao, A., J. A. Bonet, J. Martínez de Aragón, and S. deMiguel. 2017. Is silviculture able to enhance wild forest mushroom resources? Current knowledge and future perspectives. Forest Ecology and Management 402:102-114.

Tormo, J., B. Moreira, and J. G. Pausas. 2014. Field evidence of smoke-stimulated seedling emergence and establishment in Mediterranean Basin flora. Journal of Vegetation Science 25:771-777.

Torrecillas, E., M. M. Alguacil, and A. Roldán. 2012. Host preferences of arbuscular mycorrhizal fungi colonizing annual herbaceous plant species in semiarid Mediterranean prairies. Applied and Environmental Microbiology 78:61806186.

Torres, I., B. Pérez, J. Quesada, O. Viedma, and J. M. Moreno. 2016. Forest shifts induced by fire and management legacies in a Pinus pinaster woodland. Forest Ecology and Management 361:309-317.

Touchan, R., C. Baisan, I. D. Mitsopoulos, and A. P. Dimitrakopoulos. 2012. Fire history in European black pine (Pinus nigra Arn.) forests of the Valia Kalda, Pindus Mountains, Greece. Tree-Ring Research 68:45-50.

Trabaud, L. 1984. Fire adaptation strategies of plants in the French Mediterranean area. Pages 63-69 in N. S. Margaris, M. Arianoutsou-Faraggitaki, and W. C. Oechel, editors. Being alive on land. Tasks for vegetation science. Springer, Dordrecht, The Netherlands.

Trabaud, L., J. Grosman, and T. Walter. 1985. Recovery of burnt Pinus halepensis Mill. Forests. I. Understorey and litter phytomass development after wildfire. Forest Ecology and Management 12:269-277.

Troia, A., and E. Laguna. 2015. On the pyrophytism in the Mediterranean area. Journal of Arid Environments 120:1-3.

Turco, M., J. Bedia, F. Di Liberto, P. Fiorucci, J. von Hardenberg, N. Koutsias, M.-C. Llasat, F. Xystrakis, and A. Provenzale. 2016. Decreasing fires in Mediterranean Europe. PLoS ONE 11:e0150663.

Tuzet, A., A. Perrier, and R. Leuning. 2003. A coupled model of stomatal conductance, photosynthesis and transpiration. Plant, Cell and Environment 26:1097-1116.

Tyree, M. T., and M. H. Zimmerman. 2002. Xylem structure and the ascent of sap. Second edition. Springer, Berlin, Germany.

Urbieta, I. R., G. Zavala, J. Bedia, J. M. Gutiérrez, J. S. S. Miguel-Ayanz, A. Camia, J. E. Keeley, and J. M. Moreno. 2015. Fire activity as a function of fire-weather seasonal severity and antecedent climate across spatial scales in southern Europe and Pacific western USA. Environmental Research Letters 10:114013.

Urli, M., S. Delzon, A. Eyermann, V. Couallier, R. L. GarciaValdes, M. A. Zavala, and A. J. Porte. 2014. Inferring shifts in tree species distribution using asymmetric distribution curves: a case study in the Iberian mountains. Journal of Vegetation Science 25:147-159.

Vadell, E., S. de-Miguel, and J. Pemán. 2016. Large-scale reforestation and afforestation policy in Spain: A historical review of its underlying ecological, socioeconomic and political dynamics. Land Use Policy 55:37-48.
Vallejo, V. R., and J. A. Alloza. 1998. The restoration of burned lands: the case of eastern Spain. Pages 91-108 in J. M. Moreno, editor. Large forest fires. Backhuys Publishers, Leiden, The Netherlands.

van Mantgem, P., and M. Schwartz. 2003. Bark heat resistance of small trees in Californian mixed conifer forests: testing some model assumptions. Forest Ecology and Management 178:341-352.

van Mantgem, P. J., J. C. Nesmith, M. Keifer, E. E. Knapp, A. Flint, and L. Flint. 2013. Climatic stress increases forest fire severity across the western United States. Ecology Letters 16:1151-1156.

van Wagner, C. E. 1973. Height of crown scorch in forest fires. Canadian Journal of Forest Research 3:373-378.

van Wagner, C. E. 1977a. Conditions for the start and spread of a crown fire. Canadian Journal of Forest Research 33:23-34.

Van Wagner, C. E. 1977b. Conditions for the start and spread of a crown fire. Canadian Journal of Forest Research 7:23-34.

van Wagner, C. E. 1993. Predictions of crown fire behavior in two stands of jack pine. Canadian Journal of Forest Research 23:442-449.

VanderWeide, B. L., and D. C. Hartnett. 2011. Fire resistance of tree species explains historical gallery forest community composition. Forest Ecology and Management 261:15301538

Varner, J. M., J. K. Hiers, R. D. Ottmar, D. R. Gordon, F. E. Putz, and D. D. Wade. 2007. Overstory tree mortality resulting from reintroducing fire to long-unburned longleaf pine forests: the importance of duff moisture. Canadian Journal of Forest Research 37:1349-1358.

Viegas, D. X., J. Piñol, M. T. Viegas, and R. Ogaya. 2001. Estimating live fine fuels moisture content using meteorologically-based indices. International Journal of Wildland Fire 10:223-240.

Vieira, D. C. S., C. Fernandez, J. A. Vega, and J. J. Keizer. 2015. Does soil burn severity affect the post-fire runoff and interrill erosion response? A review based on meta-analysis of field rainfall simulation data. Journal of Hydrology 523:452-464.

Vilà-Cabrera, A., J. Martínez-Vilalta, J. Vayreda, and J. Retana. 2011. Structural and climatic determinants of demographic rates of Scots pine forests across the Iberian Peninsula. Ecological Applications 21:1162-1172.

Villar-Salvador, P. 2016. Restoration of Spanish pine plantations: A main challenge for the 21st century. Reforesta 1:53-66.

Vines, R. 1968. Heat transfer through bark, and the resistance of trees to fire. Australian Journal of Botany 16:499.

Walker, L. R., D. A. Wardle, R. D. Bardgett, and B. D. Clarkson. 2010. The use of chronosequences in studies of ecological succession and soil development. Journal of Ecology 98:725-736.

Wells, P. V. 1969. The relation between mode of reproduction and extent of speciation in woody genera of the California chaparral. Evolution 23:264-267.

Wesolowski, A., M. A. Adams, and S. Pfautsch. 2014. Insulation capacity of three bark types of temperate Eucalyptus species. Forest Ecology and Management 313:224-232.

West, A. G., J. A. Nel, W. J. Bond, and J. J. Midgley. 2016. Experimental evidence for heat plume-induced cavitation and xylem deformation as a mechanism of rapid post-fire tree mortality. New Phytologist 211:828-838.

Wilkinson, D. M., and T. N. Sherratt. 2016. Why is the world green? The interactions of top-down and bottom-up processes in terrestrial vegetation ecology. Plant Ecology and Diversity 9:127-140.

Wirth, C., et al. 1999. Above-ground biomass and structure of pristine Siberian Scots pine forests as controlled by competition and fire. Oecologia 121:66-80. 
Woods, S. R., S. R. Archer, and S. Schwinning. 2014. Seedling responses to water pulses in shrubs with contrasting histories of grassland encroachment. PLoS ONE 9:e87278.

Zeppel, M. J. B., et al. 2015. Drought and resprouting plants. New Phytologist 206:583-589.

Zomer, R. J., A. Trabucco, D. A. Bossio, and L. V. Verchot. 2008. Climate change mitigation: A spatial analysis of global land suitability for clean development mechanism afforestation and reforestation. Agriculture, Ecosystems and Environment 126:67-80.

Zylstra, P., R. A. Bradstock, M. Bedward, T. D. Penman, M. D. Doherty, R. O. Weber, A. M. Gill, and G. J. Cary. 2016. Biophysical mechanistic modelling quantifies the effects of plant traits on fire severity: species, not surface fuel loads, determine flame dimensions in Eucalypt forests. PLoS ONE 11: e0160715. 